\title{
Modeling and Forecasting
} Industrial Electricity Demand for Saudi Arabia: Uncovering Regional Characteristics

Jeyhun I. Mikayilov, Ryan Alyamani, Abdulelah Darandary, Muhammad Javid, Fakhri J. Hasanov, Saleh T. Al Turki, Rey B. Arnaiz 


\section{About KAPSARC}

The King Abdullah Petroleum Studies and Research Center (KAPSARC) is a non-profit global institution dedicated to independent research into energy economics, policy, technology and the environment across all types of energy. KAPSARC's mandate is to advance the understanding of energy challenges and opportunities facing the world today and tomorrow, through unbiased, independent, and high-caliber research for the benefit of society. KAPSARC is located in Riyadh, Saudi Arabia.

This publication is also available in Arabic.

\section{Legal Notice}

(c) Copyright 2021 King Abdullah Petroleum Studies and Research Center ("KAPSARC"). This Document (and any information, data or materials contained therein) (the "Document") shall not be used without the proper attribution to KAPSARC. The Document shall not be reproduced, in whole or in part, without the written permission of KAPSARC. KAPSARC makes no warranty, representation or undertaking whether expressed or implied, nor does it assume any legal liability, whether direct or indirect, or responsibility for the accuracy, completeness, or usefulness of any information that is contained in the Document. Nothing in the Document constitutes or shall be implied to constitute advice, recommendation or option. The views and opinions expressed in this publication are those of the authors and do not necessarily reflect the official views or position of KAPSARC. 


\section{Key Points}

The study decomposes the potential regional impacts of the drivers, which is particularly useful for designing energy-related policy at the regional level.

The simulations are based on different electricity prices, which provide insights as to how price and other drivers will shape regional industrial electricity consumption from 2020 to 2030.

Our simulations also reveal the role of industrial output/income in shaping future industrial electricity consumption by region.

The study considers oil price fluctuations and COVID-19 effects implicitly embedded in the price and income assumptions.

Unlike studies that consider constant elasticities, this study examines the varying nature of elasticities.

The found long-run income and price elasticities of industrial electricity demand vary across regions.

In the low case scenario, we project the 2030 demand to be 11.6 terawatthours (TWh), 63.5 TWh, 0.7 TWh and 6.8 TWh for the Saudi Electricity Company's central, eastern, southern and western operating areas, respectively, with the total demand forecast to be $82.5 \mathrm{TWh}$. 


\section{Summary}

The objective of this study is to investigate Saudi Arabia's industrial electricity consumption at the regional level. We apply structural time series modeling to annual data over the period of 1990 to 2019. In addition to estimating the size and significance of the price and income elasticities for regional industrial electricity demand, this study projects regional industrial electricity demand up to 2030. This is done using estimated equations and assuming different future values for price and income. The results show that the long-run income and price elasticities of industrial electricity demand vary across regions. The underlying energy demand trend analysis indicates some efficiency improvements in industrial electricity consumption patterns in all regions. In the low case scenario, we project the 2030 demand to be 11.6 terawatthours (TWh), 63.5 TWh, 0.7 TWh and 6.8 TWh for the central, eastern, southern and western operation areas, respectively, with the total demand forecast to be 82.5 TWh. The findings of the study can be used in designing region-specific energy policies. 


\section{Introduction}

he discovery and utilization of electricity have enabled humanity to extend its innovation horizons to the point where it is now an indispensable input for a vast array of essential processes in our lives. Thus, the demand for electricity around the world has been growing rapidly. In Saudi Arabia, electricity consumption has grown by about fivefold in the past three decades, which could be driven by its considerable population growth and economic development, among other factors (SEC, 2020).

In this regard, it is of a great importance to investigate the relationship between electricity consumption and its drivers (i.e., income, price and population) as well as the anticipated effects of those factors on future electricity consumption paths. The results of such an investigation will inform policymakers, enabling better market management and more efficient utilization of various policy tools, such as optimizing the energy mix, energy prices and emission reductions (Mundaca 2017; Alkhathlan and Javid 2015).

Specifically, industrial electricity consumption is of a great importance for Saudi Arabia as the industrial sector accounts for a significant portion of the Kingdom's economy activity. The average share of the industrial value added in gross domestic product (GDP) during the period of 1990 to 2019 was slightly more than 60\% (GaStat via SAMA 2020). In addition, Saudi Vision 2030 highlights the industrial sector as one of the main drivers of future economic growth (Saudi Vision 2017). One of the vision's main goals is the realization of the National Industrial Development and Logistics Program (NIDLIP), which aspires to transform the Kingdom into a leading industrial power. The program launched in January 2019 to promote the development of industry and logistics and to establish private sector jobs. The program also aims to enlarge the sector's share in
GDP, exports and local content. The program plans to invest 1.7 trillion SAR and create 1.6 million jobs in industry, non-oil energy, mining and logistics activities by 2030 (NIDLIP 2019). Another realization program, the Fiscal Sustainability Program, highlights the importance of energy price reform (EPR) in fostering efficient energy consumption and enhancing public budget revenues. However, the program also outlines an industrial support package to protect the sector from potential effects of the reform (FBP 2019). Thus, the success of EPR in enhancing consumption efficiency while mitigating any potential effects on industry (at both the aggregate and regional levels) necessitates a clear understanding of the effects of price reforms on energy consumption. Finally, policymakers need industrial electricity demand projections for the coming years to make efficient decisions given recent global changes, such as the oil price drop and COVID-19 pandemic.

However, insights from the analysis of the economy-wide aggregate industrial energy demand would not be so useful for policy analysis. This is because the regional consumption patterns are significantly different from each other. This implies that a 'one size fits all' type of policy implementations would be inefficient. Thus, region-specific policy measures should be designed. This is true for both demand- and supply-side management of industrial electricity in each region.

Considering the importance of the points discussed above, the objective of this study is to model regional industrial electricity demand to uncover region-specific characteristics and make projections for the coming years.

To conduct the regional analysis, we employ the Saudi Electricity Company's (SEC's) operating areas. The SEC divides Saudi Arabia into four 
Figure 1. The SEC's operating areas.

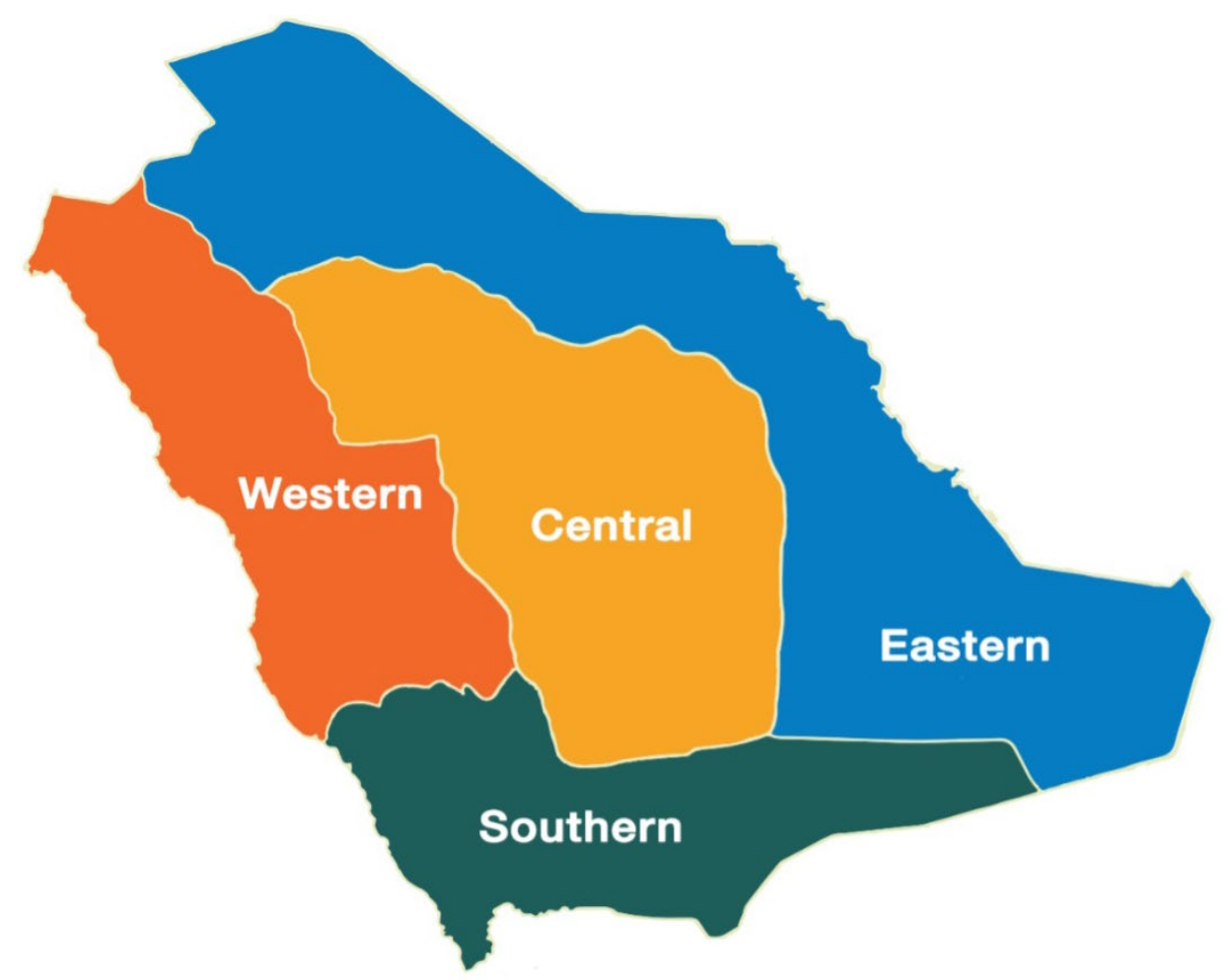

Source: The Saudi Electricity company annual report, 2015.

regions - central operation area (COA), western operation area (WOA), eastern operation area (EOA) and southern operation area (SOA) - as shown in Figure 1 above.

We employ structural time series modeling (STSM) in the cointegration and equilibrium correction framework. We also project industrial electricity demand by region for 2020 through 2030 . The estimated income and price elasticities as well as the projections could help decision-makers/ authorities better comprehend the role of these indicators in shaping regional electricity demand. This could also help supply-side planners in providing the amount of electricity needed to meet future industrial electricity demand by region.
Moreover, by highlighting the regional differences, the results could demonstrate for decision-makers and others the importance of considering these differences when designing region-specific policies.

Policymakers should expect that EPR will lower industrial electricity consumption, but not by a great extent because the price effect is very small. At the same time, they should consider that the growing industrial economic activity will lead to increased industrial electricity demand in all regions. Finally, although interventions including policy shocks can cause deviations of regional industrial electricity demand from its long-run path, the industries are capable of absorbing these interventions in less than a year. 
This study contributes to the literature on Saudi Arabia's industrial electricity demand in the following ways: a) To our knowledge, it is the first paper to investigate Saudi industrial electricity demand at the regional level, although a few papers have examined the topic at the aggregate level. b) The study decomposes the potential regional impacts of the drivers, which is particularly useful for drafting energy-related policy at the regional level. Our simulations are based on different electricity prices, which provide insights as to how they together with other drivers will shape regional industrial electricity consumption from 2020 to 2030 . Our simulations also reveal the role of industrial output/income in shaping future industrial electricity consumption by region. Additionally, this study considers oil price fluctuations and COVID-19 effects implicitly embedded in the price and income assumptions. c) Finally, unlike studies that consider constant elasticities, this study examines the varying nature of elasticities.
The remainder of this paper is divided into a further seven sections: Section 2 provides a background on the evolution of the Saudi industrial sector as well as the industrial electricity consumption in the Kingdom's regions. Section 3 highlights our findings from the literature review. Section 4 details the theoretical framework and summarizes the methodology and data. Section 5 presents the empirical results. Section 6 provides an analysis of the study's findings. Section 7 provides and discusses forecasting exercises at the regional level and section 8 concludes the paper and discusses the study's policy implications. 


\section{Background}

\subsection{Evolution of the Saudi industrial sector}

Developing the non-oil sector and diversifying the economy is at the heart of Saudi Vision 2030, which consists of 12 realization programs (Saudi Vision, 2017). One of the most pivotal programs is the National Industrial Development and Logistics Program (NIDLP). According to the vision, "The program is mandated to transform the Kingdom of Saudi Arabia into a leading industrial powerhouse and a global logistics hub in promising growth sectors" (Saudi Vision, 2017). In doing so, it aims to specifically focus on four sectors: industry, mining, energy and logistics. This objective is expected to have a positive impact on economic diversification, the balance of payments and national income. It is also expected to increase local content and create employment opportunities for local talent.

Although the Saudi government has just recently introduced its grand transformational plans for the industrial sector through the NIDLP, manufacturing processes have existed in the economy since the 1950s. It began with cement factories in the western region, as the country was undergoing rapid economic expansion. Five industries existed in 1954, with a total investment of approximately \$12 million. Industrial activity before 1970 played a small role in the Saudi economy (El Gammal and El-Bushra, 1986).

During the First Development Plan (1970-1975), significant attempts to build and operate modern industrial complexes began. Leveraging its oil resources, the government enhanced its investment in the industrial sector, intending to carry out heavy manufacturing. The government established the Saudi Arabian Basic Industries Corporation
(SABIC) in 1976 and the General Petroleum and Mineral Organization (PETROMIN) in 1968. International companies were keen to take part in these companies and pumped capital through partnerships from companies such as Exxon, Shell and Dow. By 1975, the number of establishments rose to 473 , with investments totaling $\$ 3$ billion (Gammal and El-Bushra, 1986). By the early nineties, chemical products had become the leading manufacturing sector.

In 2001, the government established the Saudi Authority for Industrial Cities and Technology Zones, also referred to as MODON, to support the Saudi industrial sector by encouraging the development of existing local industries and attracting value-added investments, from both local and international sources. To achieve this, it provides a variety of incentives, products and services. These incentives include competitive utility rates, reduced real estate prices and tax exemptions for imported machinery (MODON 2020). MODON has made a significant impact since its establishment; it currently oversees 35 existing industrial cities with 3,500 productive factories, employing about half a million workers (Saudi Press Agency 2020). These industrial cities are geographically distributed throughout the country (see Appendix A for a chart of these cities, categorized by SEC regions). Although all these industrial cities were developed by the government, the private sector has also had an active role in establishing industrial cities such as the Rabigh conversion industrial park in the western region (Petro Rabigh 2020).

Additionally, to finance the growing industrial sector, the government has established the Saudi Industrial Development Fund (SIDF), which provides low interest rate loans to factories as well as other services such as consulting (SIDF 2020). 
Figure 2. Evolution of real industrial-sector value-added and industrial electricity consumption (Normalized Scale).

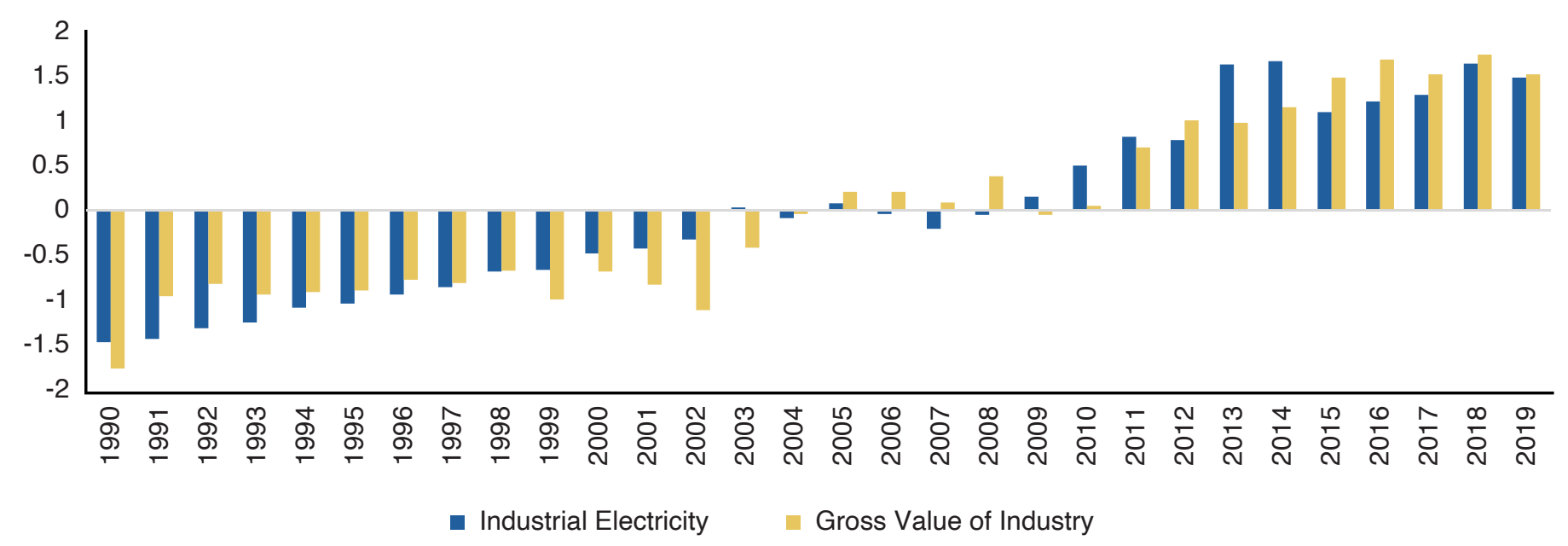

Source: SEC and GaStat via SAMA, 2020.

\subsection{Industrial electricity demand and industry types}

The Saudi economy produces a wide range of intermediate and final goods to meet the demand of its growing businesses and population. However, the electricity consumed by the industrial sector to produce this output has also grown drastically over the past three decades. Even though the gross value added (GVA) of the industrial sector has almost doubled over the past three decades, the growth of industrial electricity consumption has outpaced output for a significant number of years, as highlighted in Figure 2.

The industrial electricity consumption share, out of total electricity consumption, was 18\% in 2019 (SEC via SAMA, 2020). However, within this share, a regional disparity is clear. The EOA region consumed the highest share of industrial electricity in $2019(72 \%)$, followed by COA (14\%), WOA (13\%) and SOA (1\%) (Table 1).
In addition, examining industrial electricity consumption relative to other regional customer types reveals another layer of regional heterogeneity. For example, in 1990, the highest consuming region's (the EOA) share of industrial electricity was $63.7 \%$ of total electricity consumed in the region. By 2019 the ratio dropped to $42.9 \%$, most likely due to efficiency improvements, among other factors. Conversely, other regions saw an increase in the share of industrial consumption within their respective region.

Considering the International Standard for Industrial Classifications (ISIC), we find that the manufacturing industry type accounts for $62 \%$ of all industrial electricity consumption in the Kingdom in 2018. It also dominates all other industrial sectors in terms of the number of firms, as shown in Figure 3. The industrial electricity sales for mining and quarrying come second at $30 \%$, followed by utilities and then water supply. However, in terms of the number of firms, those three industry types represent a similarly low percentage (1-2\%) of the total number of industrial firms (Figure 3). 


\section{Background}

Table 1. Regional statistics on industrial-sector size and electricity consumption.

\begin{tabular}{|c|c|c|c|c|c|c|}
\hline \multirow[t]{2}{*}{ Regions } & \multirow{2}{*}{$\begin{array}{c}\text { Industrial } \\
\text { electricity } \\
\text { consumption } \\
\text { in } 2019 \\
\text { (Terawatt-hour) }\end{array}$} & \multicolumn{2}{|c|}{$\begin{array}{c}\text { Annual average growth rate } \\
\text { between } 1990 \text { and } 2018\end{array}$} & \multirow{2}{*}{$\begin{array}{l}\text { Share of total } \\
\text { industrial } \\
\text { electricity } \\
\text { consumption, } \\
2019\end{array}$} & \multirow{2}{*}{$\begin{array}{l}\text { Share of total } \\
\text { Industrial } \\
\text { firms, 2018 }\end{array}$} & \multirow{2}{*}{$\begin{array}{l}\text { Share of total } \\
\text { Industrial } \\
\text { employment, } \\
2018^{a}\end{array}$} \\
\hline & & GDP & $\begin{array}{c}\text { Industrial } \\
\text { electricity } \\
\text { consumption }\end{array}$ & & & \\
\hline COA & 6.9 & $3.4 \%$ & $7.9 \%$ & $14 \%$ & $32 \%$ & $34 \%$ \\
\hline WOA & 6.6 & $2.9 \%$ & $8.7 \%$ & $13 \%$ & $36 \%$ & $27 \%$ \\
\hline EOA & 35.3 & $2.8 \%$ & $3.1 \%$ & $72 \%$ & $20 \%$ & $34 \%$ \\
\hline SOA & 0.6 & $3.1 \%$ & $9.7 \%$ & $1 \%$ & $12 \%$ & $5 \%$ \\
\hline
\end{tabular}

Notes: GDP values are regional from Lopez-Ruiz, Blazquez and Hasanov (2019). a = data is only available for 2018.

Source: GaStat (2018) and SEC and GaStat via SAMA 2020.

Figure 3. Composition of industry types based on industrial electricity sales and number of firms.

Industrial Electricity Sales by Industry Type

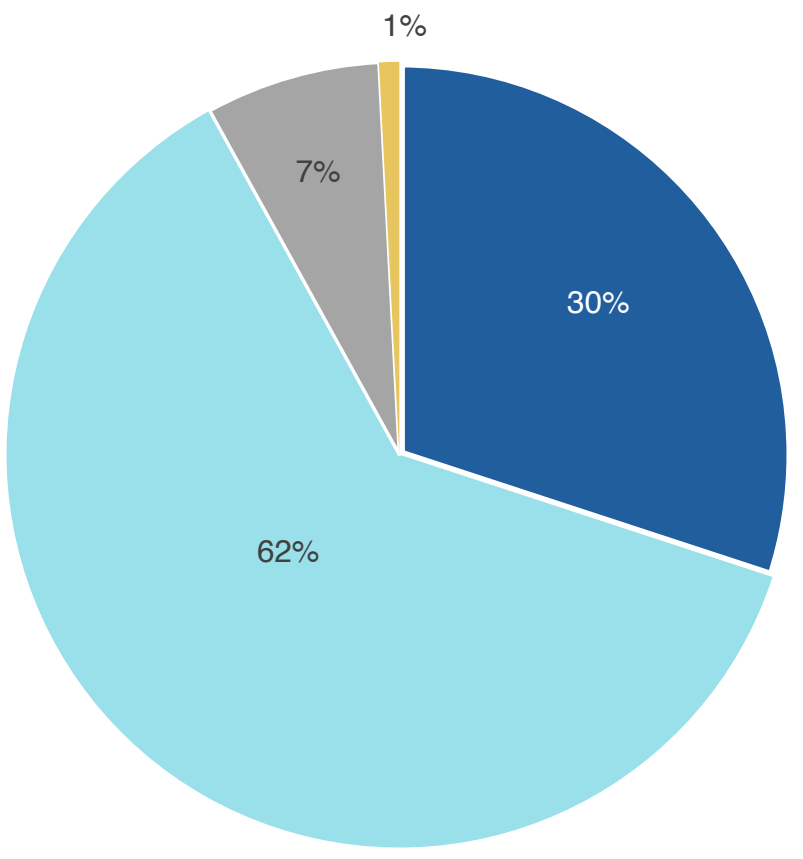

Total Sales $=23.2$ Billion SAR

Mining and quarrying

Electricity, gas, steam and air conditioning supply
Number of Industrial Firms by Industry Type

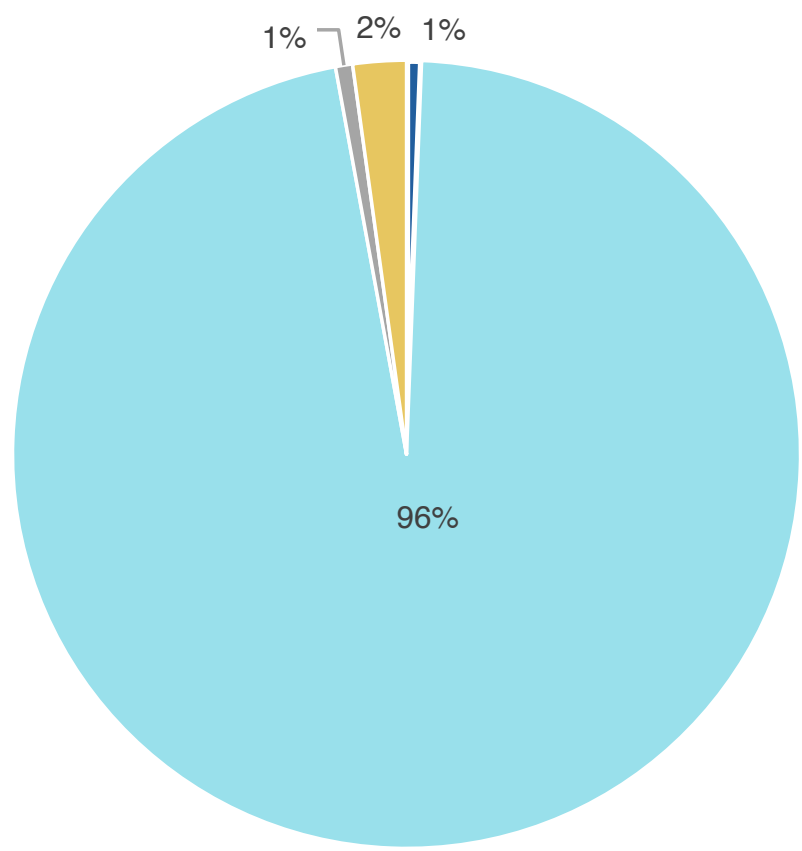

Total Firms $=112.8$ thousand

Manufacturing

Water supply; sewerage, waste management and remediation activities

Source: GaStat 2018. 


\subsection{Regional heterogeneity and characteristics}

As mentioned previously, the manufacturing sector used the largest share of electricity for industrial purposes in 2018, followed by mining and quarrying. Together these industry types consumed approximately SAR 21 billion, $92 \%$ of total electricity sales in 2018, as reported in the General Authority for Statistics Industrial Survey (GaStat 2018). Figure 4 shows the percentage change in electricity consumption from 2014 to 2019. The figure illustrates the concentration and distribution of electrical consumption by region, underscoring the rationale behind modeling regional industrial electricity consumption. It is noticeable that the four regions in Saudi Arabia do not change harmoniously, highlighting that, fundamentally, they react differently to the same set of explanatory factors. These differences can largely be explained by the industrial composition of each sector, as discussed in section 2.2.

Figure 4. Year-over-year percentage change in industrial electricity per region.

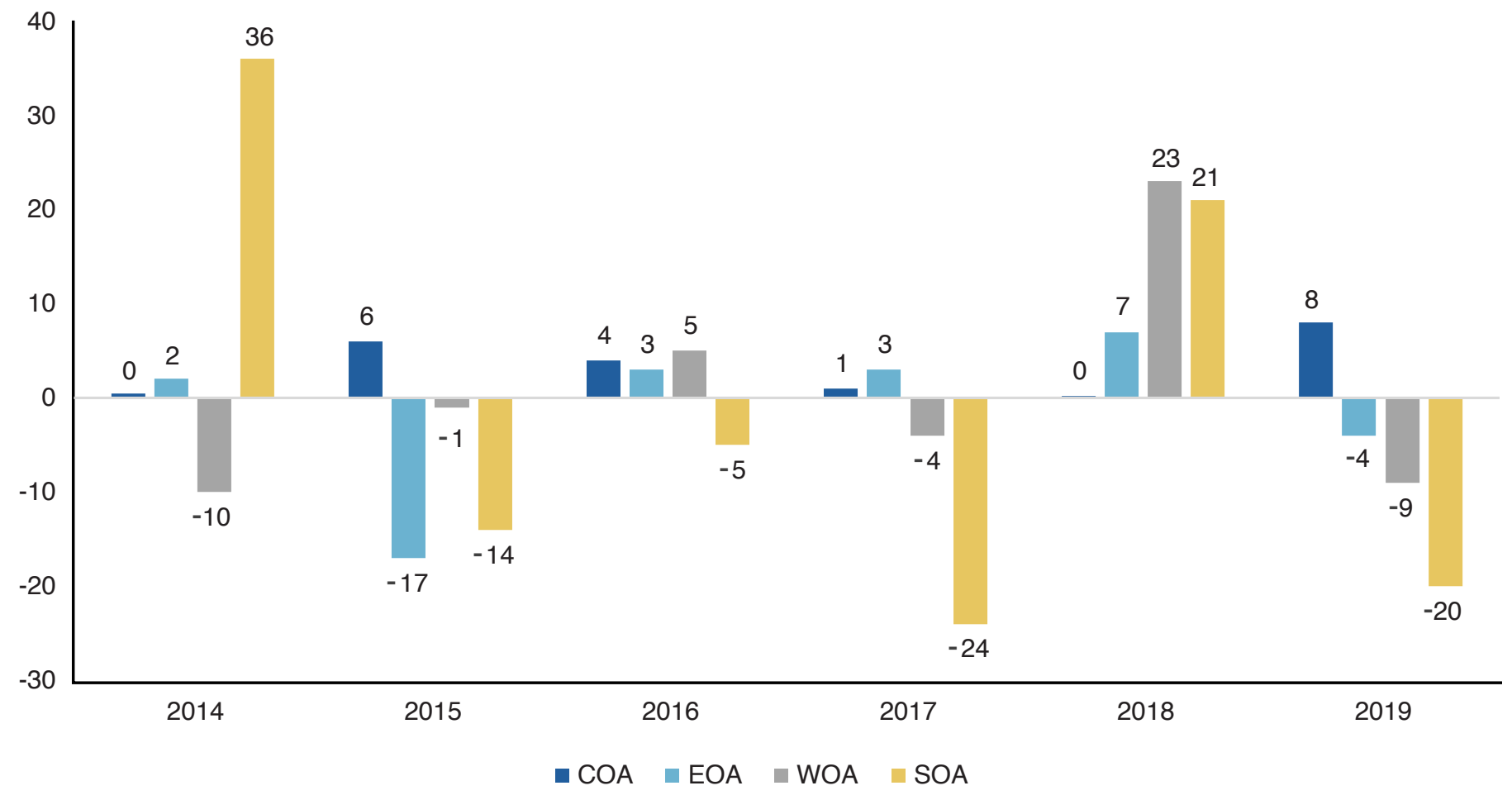

Source: SEC via SAMA (2020). 


\section{Background}

Although all the regions contain all four industry types, the sizes of the regional industrial sectors and their associated electricity use are heterogeneous with regard to consumption and growth (GaStat 2018; SEC via SAMA 2020). These differences could be driven by the region's unique characteristics, which attract some industry types more than others based on a variety of factors, including the geographical location and topography, access to labor, logistics, real estate availability and prices, supporting industries, market size and availability of resources. These factors are important for explaining the distribution of industrial activity and, ultimately, electricity consumption. For example, some industries are by nature more energy intensive, such as the manufacturing of chemicals and chemical products, coke and refined petroleum products that rely on export revenue and would need be situated in areas with easy access to world trade, such as ports and borders with neighboring countries. In contrast, some industries are bounded by the availability of resources endowed in the region, such as the oil endowment in the EOA. In Table 1 and Table A1 in Appendix, we present an overview of the regions' characteristics and industrial consumption patterns.

The central operating area (COA) lies at the center of the country and is home to the capital city of Riyadh, which houses all government ministries. The region has experienced the highest economic growth in the past three decades when compared with other regions (Lopez-Ruiz, Blazquez, and Hasanov 2019). It employs half of the Kingdom's workers in electricity, gas and water-related industries, which could be driven by the region's lack of water access due to its geography (GaStat 2018). In total, the region employs the second highest number of workers in the industrial sector, while it is the highest when it comes to the manufacturing sector (GaStat 2018). In terms of number of firms
$(35,960)$, it is the second-highest region in the Kingdom (GaStat 2018), and it holds 11 of the MODON industrial cities. Geographically, the region is isolated from trade access, so the majority of industrial customers are local. For instance, the top five concentrated industries, in terms of numbers, for the COA are manufacturing of paper products, computer, electronic and optical products, electronic equipment, motor vehicles, trailers and semi-trailers and other transport equipment. At the national level, these local revenues from these industries make up $83 \%$ of the sales of goods (GaStat 2018). Due to data limitations, national values are used as an approximation because the COA represents the largest weight for these industries.

The eastern operation area (EOA) is known most notably as the headquarters of Aramco. It has been historically on the frontier of the Saudi industrial sector, primarily within the mining and quarrying sectors. Extraction of crude oil and natural gas consumed the highest portion of industrial-sector electricity in 2018 and it undoubtedly requires supporting industries to be within its vicinity. Ultimately, the electricity use of the industrial sector in the EOA is the highest, consuming $72 \%$ of total (SEC via SAMA 2020) industrial electricity in the country in 2019. Although the region only holds $20 \%$ of the Kingdom's industrial firms, it contains the lowest percentage of small/micro-firms, indicating that the region is well established around mature firms. For instance, the EOA is home to the world's largest industrial city, Jubail (Chepkemoi 2019). Established in 1975 by Royal Decree (KSA 1975), the city extends 1,016 square kilometers, which includes industrial and petrochemical complexes. It is also home to the industrial operations of the largest petrochemical firm in the world, SABIC. SABIC plays a significant role in Saudi Arabia's economy, contributing approximately $12.8 \%$ in GVA in manufacturing, $3.7 \%$ to private sector GDP and 
$1.7 \%$ to total GDP in 2018 (SABIC 2018). Moreover, in 2019, the Jubail desalination plant was recognized as the largest producer of desalinated water in the world, producing 1.4 million cubic meters daily (GWR 2019).

The number of industrial firms in the EOA is fewer than in other regions. However, it employs the highest number of workers across all industries. The region has experienced the lowest average annual growth in industrial electricity demand over the past three decades, as highlighted in Table 1. In terms of the ISIC industry type, the region has the highest number of firms working in the mining and quarrying sector; it employs $84 \%$ of all those working in mining and quarrying around the Kingdom. It also contains a relatively high number of manufacturing firms, second to the western region.

The southern operation area is the smallest industrial sector in the Kingdom, which is reflected in its number of industrial firms, industrial electricity consumption and amount of industrial employment in the region. Further, the overwhelming majority $(91 \%)$ of the industrial firms are classified as micro (1-5 employees) or small (6-49) industrial firms. Consequently, these firms are less flexible and have changing cost structures. The industrial survey reports that 19\% of micro- and small firms in 2018 faced challenges with respect to production cost.

However, the region has experienced the second-highest growth in electricity consumption in the past three decades, especially after the introduction of the MODON initiative, which established four industrial cities in the region. Nonetheless, in terms of electricity usage, of the industries existing in the SOA, a few sectors consume a large amount of electricity. The most prominent of these are manufacturing of food products and fabricated metal products. The southern operation area is also home to Jizan, which is an economic city launched in 2006 with a $\$ 26.7$ billion investment. It localizes heavy industries, petrochemical industries, mining industries and downstream industries. In addition, it provides bio-energy supply, localized ship manufacturing and takes advantage of minerals, agriculture, wildlife and fish resources. The port of Jizan is considered Saudi Arabia's third most important port on the Red Sea. It offers access to eastern and western maritime trade routes between Europe, the far East, the Arabian Gulf and East Africa. In 2018, Aramco announced that it is building a 400,000 barrel per day refinery in Jizan (Saudi Aramco 2016).

The western operation area has experienced the highest industrial electricity growth in the past three decades (SEC via SAMA, 2020). Compared with the other regions, the western operation area has the highest number of industrial firms. Notably, it has the highest number of water supply manufacturing firms, which are supported by the region's strategic location along the Red Sea coast (GaStat 2018). The Red Sea offers route access to trade, and this exportability could be a strong factor in the distribution of industrial sectors. Additionally, the region is home to the largest number of industrial firms, 40,616 . It employs $27 \%$ of all industrial sector employees nationally. One statistic stands out in the share of firms in the region, their sizes. The region has the highest share of medium-sized firms ${ }^{1}$ compared with the other regions. Within the disaggregated manufacturing sectors, as of 2018 , the WOA's firms concentrate on the manufacturing and preparation of pharmaceutical products; repair and installation of machinery and equipment; and water collection, processing, supply and sanitation. Except for crude oil and natural gas, the region is quite well distributed among all the manufacturing sectors. When it comes to industrial electricity 
consumption, the WOA has the highest number of industrial firms (36\% of total). In particular, it has a high concentration of sectors that are large consumers of the total energy bill (GaStat 2018), such as manufacture of coke and refined petroleum products, manufacture of chemicals and chemical products and manufacture of food products.
The region is also home to Yanbu industrial city, the Jubail equivalent of the western operation area. A 605 square kilometer city, with output that is intended for export, primarily focusing on petrochemicals, oil refining and plastic facilities (YIC Quarter report 2016), Yanbu industrial city is the last station for oil and liquified natural gas pipelines, stretching almost 1,200 $\mathrm{km}$ from the eastern province. 


\section{Literature Review}

n many modern economies, energy is arguably the most important component in the production of goods and services. In recent years, the deregulation of the energy sector, the high price volatility of energy products, technological innovation, energy efficiency policies and policies related to climate change and energy security have fostered research interest in industrial electricity demand modeling. Robust knowledge of the income and price elasticities of industrial electricity demand could facilitate a better understanding of the economic consequences of fluctuating prices and help with the formulation of effective policies on energy and environmental issues. In the existing literature, different dimensions and methodological approaches have been used for the econometric analysis of industrial energy demand modeling. Among these approaches time varying and fixed coefficient specifications, asymmetric price responses (ARP) and technical changes are the most prominent.

In most of the earlier studies, a single equation approach with fixed coefficients is used to model industrial energy demand. The energy price and income are widely used as potential explanatory variables under the assumption of symmetric price elasticity (Dilaver and Hunt 2011; Chang et al. 2014). Some of these studies are summarized in Table 2. However, recent literature has criticized the assumption of a constant price elasticity (Dargay 1992; Hughes, Knittel, and Sperling 2008; Inglesi-Lotz 2011; Arisoy and Ozturk 2014; Chang et al. 2014; Adeyemi and Hunt 2014; Wang and Mogi 2017; Liddle and Hasanov 2021). These studies argue that estimates of constant elasticity represent the average over time and that these estimates do not capture how elasticities vary over time. Liddle and Hasanov (2021) indicate that energy intensity initially increases as low-income countries expand their industrial base and then decreases over time as countries experience a sectoral shift from energy-intensive heavy industry to light industry or less energy-intensive services. Therefore, the relationship between energy demand and its main determinants may vary in response to changes in economic structure over time, technological development, improvements in electricity equipment, government energy policies, stages of economic development and the persistence of consumer habits (Chang and Martinez-Chombo 2003; Arisoy and Ozturk 2014; Mikayilov et al. 2017). Moreover, the relationship between industrial electricity demand, income and prices might not remain constant over time (Park and Hahn 1999; Park and Zhao 2010; Liddle and Hasanov 2021).

To address the problem of non-linearity in the price and income elasticities, many recent studies have used the time-variable coefficient (TVC) approach (see Park and Zhao 2010 for the USA; Inglesi-Lotz 2011 for South Africa; Neto 2012 for Switzerland; Arisoy and Ozturk 2014 for Turkey; Chang et al. 2014 for Korea; Wang and Mogi 2017 for Japan; Mikayilov et al. 2017 for Azerbaijan; Liddle and Hasanov 2021 for a panel of middle-income countries). Time-variable parameter models can detect structural changes and outliers with parameter drift and auxiliary residuals (Durbin and Koopman 2012).

One strand of the literature claims that technical progress can influence energy demand exogenously. Hunt, Judge, and Ninomiya (2003a, b) argue that exogenous technological progress can be captured by a stochastic trend, rather than by a linear trend as suggested by Kouris (1983a, b) and Beenstock and Willcocks (1981, 1983). Hunt, Judge and Ninomiya (2003a, b) indicate that the stochastic trend, referred to as the underlying energy demand trend (UEDT), can capture the effect of exogenous technological change as well as the effect of the persistence of habits, changes in economic 


\section{Literature Review}

structure and changes in building and environmental regulation. Huntington (2006) shows that exogenous and price-dependent technological development are important for analyzing oil demand behavior. Adeyemi and Hunt (2014) argue that the effects of endogenous technological progress can be captured through asymmetric price response (APR) while exogenous technological progress can be obtained using UEDT in time series data. After conducting a series of statistical tests across different specifications, Adeyemi et al. (2010) concluded that the role of the APR and energy-saving technological change through UEDT (a stochastic trend in the time series context) cannot be excluded. Agnolucci (2010) estimates the energy demand function for the industrial and household sectors in the U.K. using three different estimation approaches: a linear-deterministic trend model, a price decomposition model and the STSM approach. The study concluded that STSM is an effective approach to estimating energy demand modeling.

In the context of Saudi Arabia, there is little literature that focuses on industrial electricity demand. The three studies that we are aware of are Hasanov (2019), Hasanov and Mikayilov (2020) and Hasanov et al. (2020). Hasanov (2019) revisits a theoretical framework to study the relationship between industrial electricity consumption and demographic and economic factors. The study concluded that there is a long-term relationship between industrial electricity consumption and industrial value added, electricity price and the population aged 15-64 years. In their preferred model, Hasanov and Mikayilov (2020) find a significant influence of the price of labor, price of capital and price of electricity on non-oil industrial electricity consumption in Saudi Arabia. Hasanov et al. (2020) examine the price and income elasticity of industrial electricity demand for Saudi Arabia during 1985-2016 by using a fully modified ordinary least squares (FMOLS) approach. They find the long-run income and price elasticities are 0.47 and -0.32 , respectively, while the short-run price elasticity is -0.11 . However, Hasanov (2019), Hasanov and Mikayilov (2020) and Hasanov et al. (2020) ignore the role of endogenous and exogenous technological progress in modeling industrial electricity demand for Saudi Arabia. Similarly, the empirical estimates of these studies assume a constant price elasticity of industrial electricity demand. The assumption of a constant price elasticity of industrial electricity demand needs to be tested in the case of the Saudi economy because industrial electricity consumption, electricity prices and the overall economy of Saudi Arabia have been subject to considerable structural changes over time. This is an important limitation of the existing literature on industrial electricity demand in Saudi Arabia, which we will consider in this research.

In Table 2, we compare the results of existing literature in terms of the income and price elasticities of industrial electricity demand for various regions. The various methodological approaches used in these studies are also noted. The reported elasticities in Table 2 show considerable variation in the estimated income and price elasticities of industrial electricity demand across different income groups and countries.

This variation in elasticities may be due to different data sets, the methodology used or the different time spans used for the empirical analyses. Country and region-specific economic structures may also be a possible reason for different income and price elasticity estimates. We are not aware of any study investigating industrial electricity demand for Saudi Arabia at the regional level. The available studies only consider total industrial electricity demand for Saudi Arabia. Furthermore, they are based on the assumption of a constant price elasticity of 

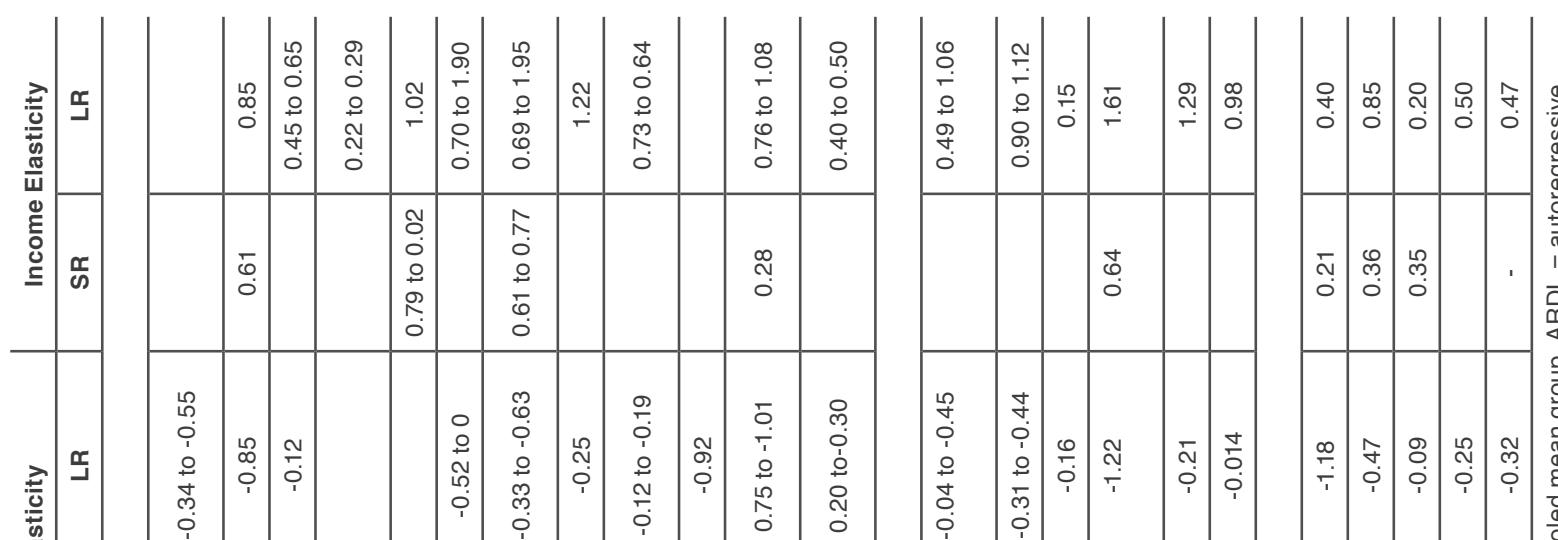

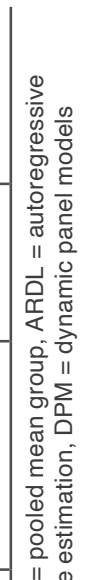

늘

离 $\frac{11}{2} \frac{\pi}{\overline{3}}$

II 흥을

ᄂ 号

岇흐응

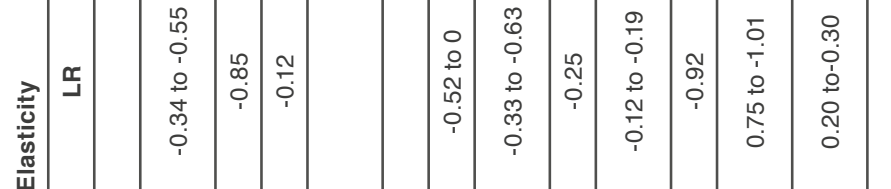

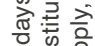

$\Phi$

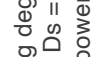

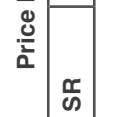

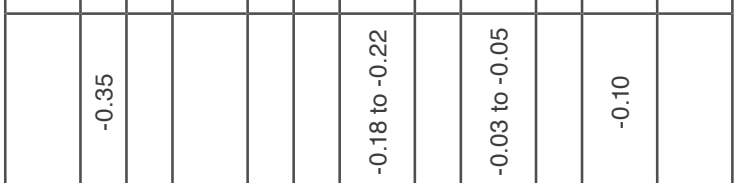

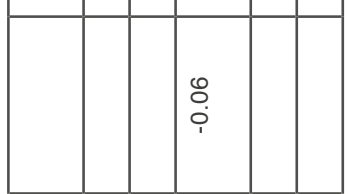

$\bar{\complement} \widehat{ِ}$

$=\sum_{0}$

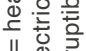

定要

究言要

离

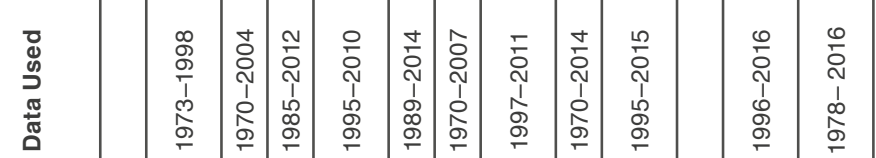

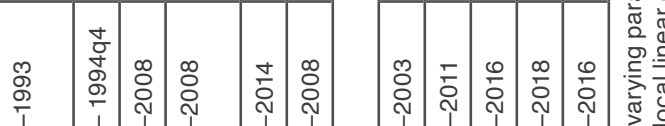

ब 50

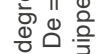

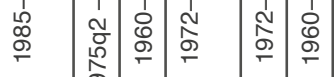

然

至

II

"1 0 वे

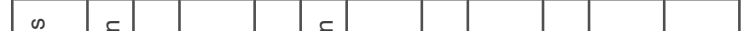

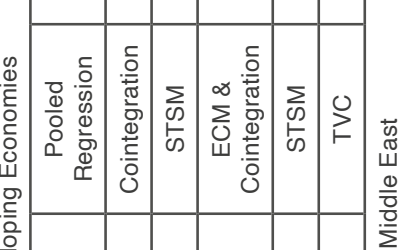

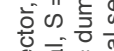

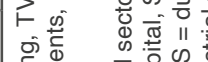

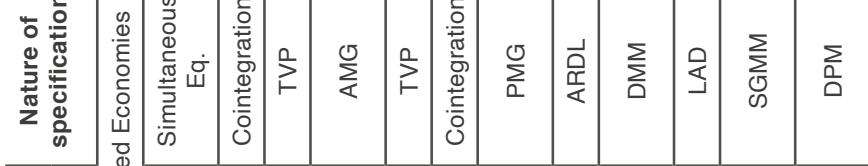

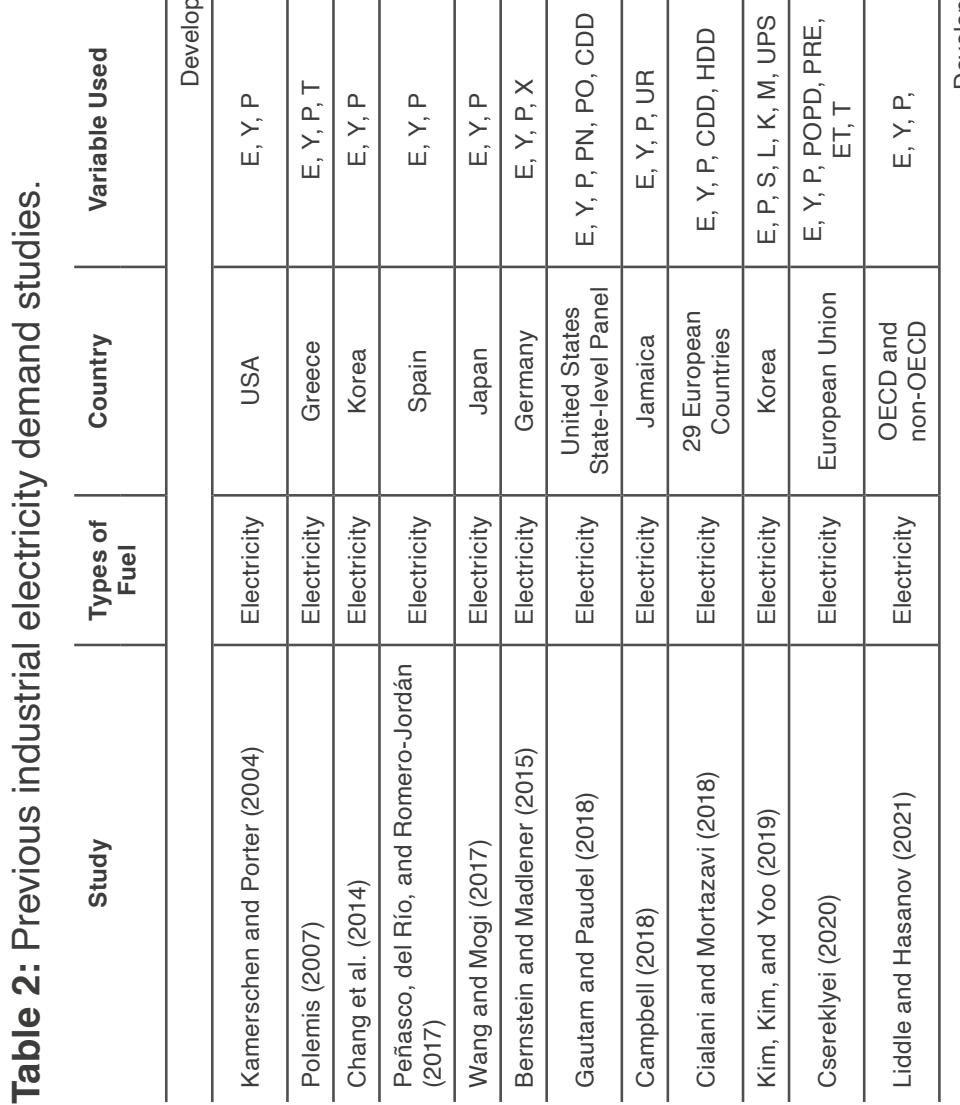

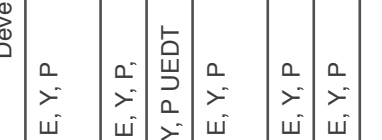

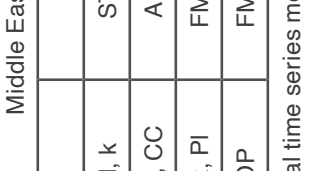

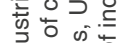

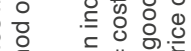

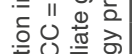

每

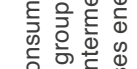

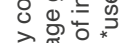

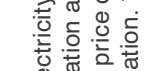

$\sum$

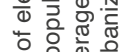

에

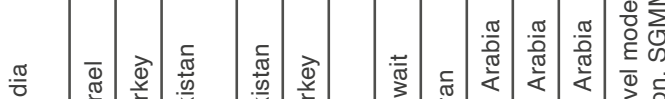

이일 $\sum^{11}$

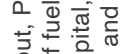

윻휴 등

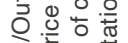

잉

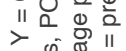

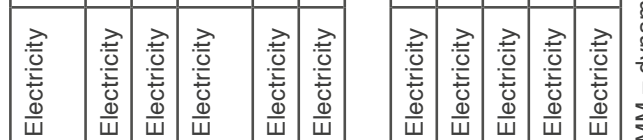

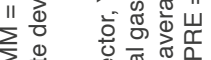

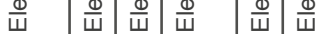

$\frac{\Phi}{\Psi} \frac{\Phi}{\Psi} \frac{\Phi}{\Psi} \frac{\Phi}{\Psi} \frac{\Phi}{\Psi}$

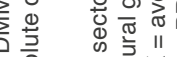

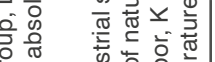

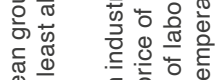

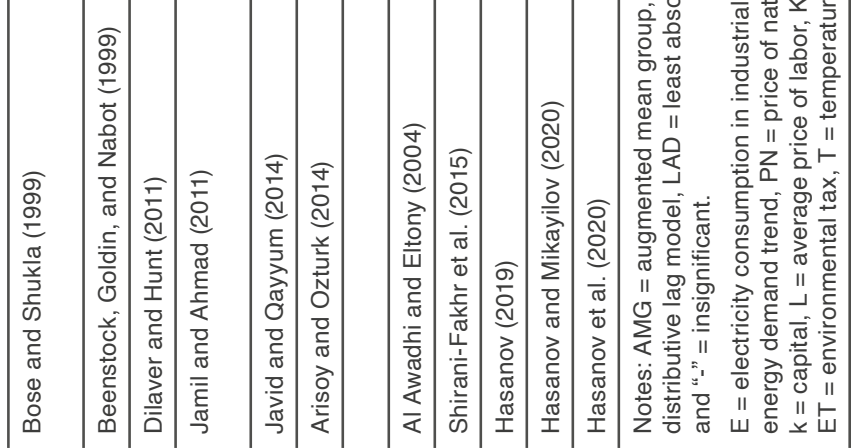


industrial electricity demand and they ignore the role of technological innovation in industrial electricity demand modeling. We address all the above-listed limitations of the previous studies in our research. Regarding projecting future values by forecasting industrial electricity demand, we are aware of only one recent study, namely Hasanov (2019). This study, however, forecasts projected total industrial electricity demand, not regional demand. Hence, this study also aims to make forecasts for future industrial electricity demand at the regional level for the four regions of Saudi Arabia. 


\section{Materials and Methods}

\subsection{Theoretical framework}

Hasanov and Mikayilov (2020) note that it is theoretically coherent and empirically important to consider potential factors that drive energy demand. However, many extant studies consider only income and price. They empirically argue that not following theoretical articulations combined with data insights in the general to specific modeling framework can lead to incorrect conclusions about the energy demand process at hand. Therefore, several studies consider other factors that can shape energy demand alongside income and price, such as demographic indicators, capital stock and labor, in their energy demand analyses. Regarding the demographic factors, several energy demand studies consider indicators, such as population, age groups and urbanization (see, e.g., Halvorsen 1972; Holtedahl and Joutz 2004). Particularly for industrial electricity consumption modeling, studies such as Mount et al. (1973), Burke and Abayasekara (2017) and Hasanov (2019) consider demographic variables alongside economic variables. Based on seminal studies in the field, such as Nordhaus (1975) and Beenstock and Dalziel (1986), Hasanov (2019) revisits a theoretical framework, where the working-age population, together with income and price, determines industrial electricity demand. $\mathrm{He}$ also discusses potential channels through which demographic variables can impact industrial energy demand. In addition, Campbell (2018) finds that demographic indicators can impact industrial electricity consumption, independent of income and price. Given the above, it appears that an analysis of the demographics of industrial electricity consumption is worth considering. Moreover, some seminal studies, such as Beenstock, Goldin, and Nabot (1999), use temperature data in their industrial electricity demand analysis while Dilaver and Hunt (2011) include underlying energy demand trends, alongside income and price measures, in their theoretical discussion. Thus, the preferable theoretical framework for us to consider would be as follows:

$$
D e_{t}=f\left(Y_{t}, P_{t}, D M_{t}, T E_{t}, U E D T_{t}\right)
$$

Where, $D e_{t}$ is industrial electricity consumption; $Y_{t}$ is income in real terms; $P_{t}$ is the weighted average industrial electricity price in real terms (consumption shares for different price brackets are used as shares); $D M_{t}$ is a demographic indicator, such as population; $T E_{t}$ is a temperature variable and $U E D T_{t}$ is the underlying energy demand trend (discussed in section 4.2) for industrial electricity consumption. Unlike Beenstock, Goldin, and Nabot (1999), we do not use temperature data because only a small portion $(5 \%)$ of industrial electricity consumption is used for cooling purposes in Saudi Arabia (Damoom et al. 2018). The dynamic econometric specification of the relationship, where the variables are expressed in natural logarithms, can be written as below:

$$
\begin{gathered}
d e_{t}=\alpha_{0}+\alpha_{1} d e_{t-1}+\alpha_{2} d e_{t-2}+\beta_{0} y_{t}+\beta_{1} y_{t-1} \\
+\beta_{2} y_{t-2}+\gamma_{0} p_{t}+\gamma_{1} p_{t-1} \\
+\gamma_{2} p_{t-2}+\delta_{0} d m_{t}+\delta_{1} d m_{t-1} \\
+\delta_{2} d m_{t-2}+\text { uedt }_{t}+\varepsilon_{t}
\end{gathered}
$$

The maximum lag number is chosen based on the sample size.

\subsection{Econometric methodology}

To examine the unit-root properties of the variables the study uses the augmented Dickey-Fuller (ADF) test (Dickey and Fuller 1981). The empirical estimations make use of the structural time series modeling (STSM) approach proposed by Harvey (1989). The STSM approach is detailed by Mikayilov et al. (2020), inter alia. 


\section{Materials and Methods}

In addition to treating coefficients of variables as time varying in the STSM approach, we utilize the so-called multiplicative indicator saturation (MIS) approach (Ericsson 2012; Castle, Hendry, and Martinez 2017; Castle and Hendry 2019). This approach assigns step dummies to each observation and uses the step dummies multiplied to the variable(s). Then, using the Autometrics algorithm (Doornik 2009; Doornik and Hendry 2018), it chooses the significant terms. This allows us to identify in which periods of time there was a change in a certain variable's coefficient.

We employ the cointegration tests proposed by Nyblom and Harvey $(2000,2001)$ to check the existence of a long-run relationship among the variables.

\subsection{Data}

To compute the drivers of regional industrial electricity consumption, this study uses annual data from 1990 to 2019. The following provides an overview of the variables used in the study.

Industrial Electricity Consumption is the dependent variable, defined as the regional annual industrial electricity demand in megawatt hours (MWh). The data series is sourced from the Saudi Electricity Company (SEC) for 1990-1999 and the Saudi Arabian Monetary Agency Annual statistics (SEC via SAMA, 2020) for 2000-2019. The industrial electricity consumption data series excludes electricity generated by captive plants for their own use but includes excess power sold to the grid. The SEC covers almost all transmission but not all generation; however, due to data constraints, the SEC is assumed to represent the sector across its activities (generation, transmission and distribution).

\section{Gross Value Added in the Industrial Sector} represents the aggregate real GVA of the industrial sector in Saudi Arabia from 1990 to 2019. The variable is constructed as the sum of GVA in oil extraction, GVA in manufacturing and GVA in utilities. These are sourced from GaStat via SAMA Annual Statistics (2019). Due to data limitations, there is no regional industrial GVA data. This gives rise to the question of whether total industrial value added can be used in place of the regional figures. As the variables are in logarithmic form, it can be shown that the parameters/elasticities will remain the same regardless of whether regional or total industrial value added is used. Denoting the regional GVA as $Y_{i}$, where i stands for region number, the total GVA can be expressed as follows:

$$
Y=\sum_{i=1}^{4} Y_{i}
$$

Then, considering the fact that shares of regional industrial electricity consumption (SEC via SAMA 2019) and shares of regional GVA (Lopez-Ruiz, Blazquez, and Hasanov 2019) have demonstrated nearly constant behavior over the investigation period, we can take each region's industrial GVA share in the total industrial GVA constant. The industrial GVA of region $i$ can then be expressed as follows:

$$
Y_{i}=\alpha_{i} Y
$$

and mathematically, it can be written as

$$
Y=\frac{1}{\alpha_{i}} Y_{i}=\beta_{i} Y_{i}
$$

where $\alpha_{i}$ is the share of industrial GVA of region $i$ in total industrial GVA and $\beta_{i}=\frac{1}{\alpha_{i}}$. Now, let us assume that the original mathematical model for region $i$ is

$$
L n D E_{i}=\gamma_{0}+\gamma_{1} \operatorname{Ln} Y_{i}+\gamma_{2} \operatorname{LnP} .
$$


However, due to data unavailability, we use the below model:

$$
\operatorname{Ln} D E_{i}=\gamma_{0}^{\prime}+\gamma_{1}^{\prime} \operatorname{Ln} Y+\gamma_{2}^{\prime} \operatorname{Ln} P .
$$

We want to see what the cost of using the total GVA will be. Considering (5) in (7) gives us

$$
\operatorname{LnDE} E_{i}=\gamma_{0}^{\prime}+\gamma_{1}^{\prime} \operatorname{Ln} \beta_{i} Y_{i}+\gamma_{2}^{\prime} \operatorname{Ln} P .
$$

Using the properties of a logarithmic function, (8) can be expressed as follows:

$$
\operatorname{LnDE} E_{i}=\left[\gamma_{0}^{\prime}+\gamma_{1}^{\prime} \operatorname{Ln} \beta_{i}\right]+\gamma_{1}^{\prime} \operatorname{Ln} Y_{i}+\gamma_{2}^{\prime} \operatorname{Ln} P
$$

Considering that the left-hand sides of (6) and (9) are the same and the variables on the right-hand side are the same, we can equate the left-hand sides of (6) and (9), which gives us

$$
\gamma_{1}^{\prime}=\gamma_{1}, \gamma_{2}^{\prime}=\gamma_{2} \text { and } \gamma_{0}^{\prime}=\gamma_{0}-\gamma_{1} \operatorname{Ln} \beta_{i} .
$$

As seen from equation (10), the income and price elasticities are the same in equations (9) and (6) and the only cost is the intercept, which will be underestimated in (9). If the only purpose is estimating the income and price elasticities, then there is no cost to estimating (9) instead of (6). However, if forecasting will also be performed, one should correct the intercept using intercept correction techniques, which will be used in the current study's forecasting exercises as well. In case of varying shares in (4), all the above derivations are also valid. The only point is having a nonconstant intercept in (9). In the case of non-constant shares, there will be one more variable in the equation, which is the non-constant shares. As the data on these shares are not available to us, we capture this variable by having the intercept term of the regression equation be non-constant. Estimation of a model with a nonconstant intercept might produce poor results with some estimation techniques. Hence, the use of STSM, which allows us to treat the intercept as time varying, which is more relevant for this purpose.

Industrial Electricity Price is the price of industrial electricity in Saudi Arabian Riyals (SAR) per kilowatt-hour (kWh). The prices were calculated by the authors as the weighted average of the industrial electricity prices using price data from the KAPSARC data portal (KAPSARC 2020) and consumption shares based on Saudi Arabia's Electricity and Cogeneration Regulatory Authority's data. The price data, converted to real terms using an industrial GDP deflator, are calculated by the authors using real and nominal industrial GVA from GaStat via SAMA (2019).

Table 3 provides brief statistics on the size and associated electricity consumption of each region's industrial sector. This table highlights some dimensions of regional heterogeneity.

Table 3. Distribution of industrial electricity growth across Saudi regions.

\begin{tabular}{c|c|c|c|c|c|c} 
Variable & Obs & Mean & Std. Dev. & Min & Max & Mean last 5 years \\
\hline COA & 30 & $8.0 \%$ & $8.0 \%$ & $-6 \%$ & $27 \%$ & $2.3 \%$ \\
\hline EOA & 30 & $3.3 \%$ & $8.0 \%$ & $-17 \%$ & $25 \%$ & $-1.6 \%$ \\
\hline WOA & 30 & $9.0 \%$ & $12.0 \%$ & $-10 \%$ & $43 \%$ & $3.0 \%$ \\
\hline SOA & 30 & $14.0 \%$ & $38.9 \%$ & $-61 \%$ & $126 \%$ & $-8.5 \%$
\end{tabular}

Source: SEC via SAMA 2020. 


\section{Materials and Methods}

As seen in Table 3, demand in the SOA region demonstrates substantial volatility, which is a result of public interventions to develop the industrial sector in the region. Therefore, to model demand properly for each region, different intervention dummies should be used to capture these incongruities in demand behavior.
Figure 5 provides the total and regional electricity consumption levels, in terrawatthours (TWh), in addition to the share of industrial consumption in total electricity consumption.

Figure 5. Industrial electricity consumption: total and regional.

Total

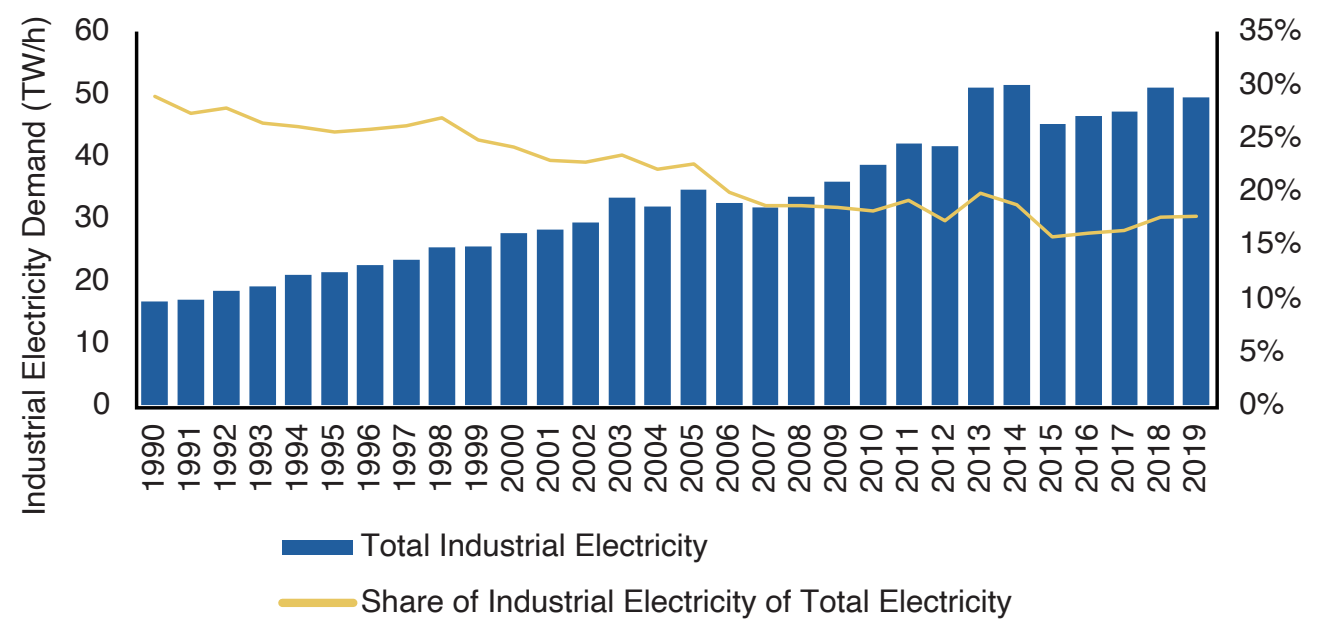

$\operatorname{COA}$

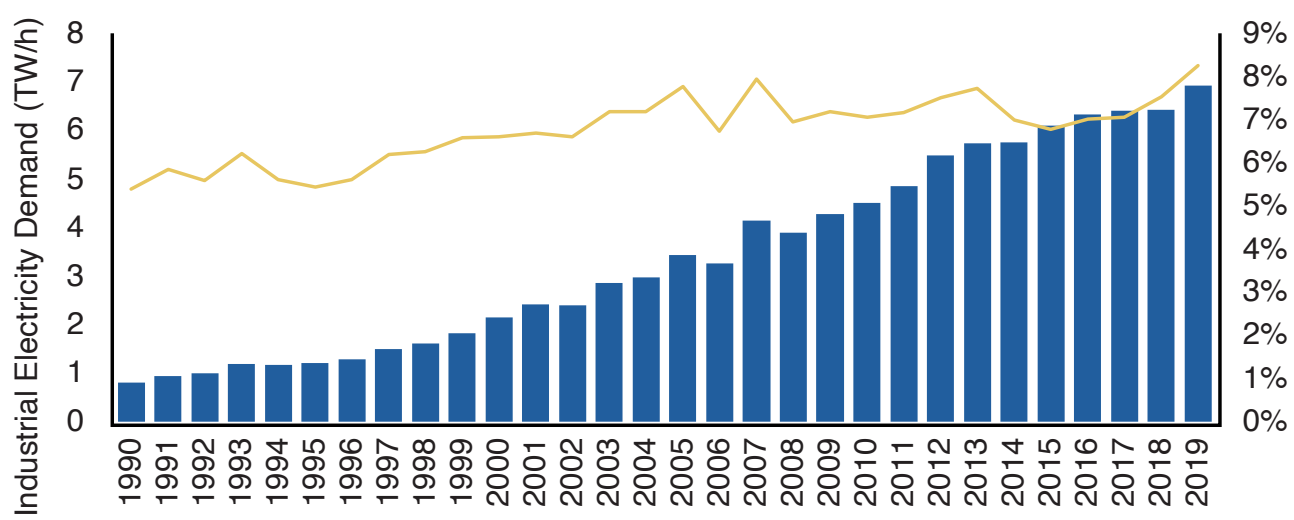

COA Industrial Electricity

COA Industrial Electricity share of Total Electricity 
EOA

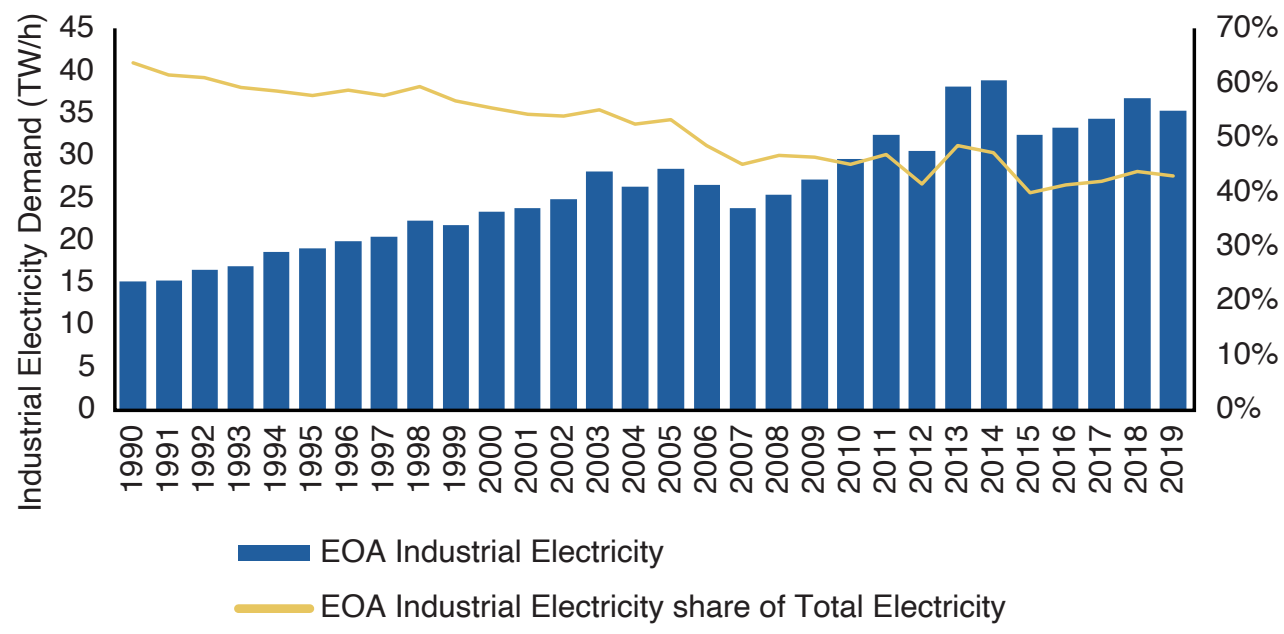

WOA

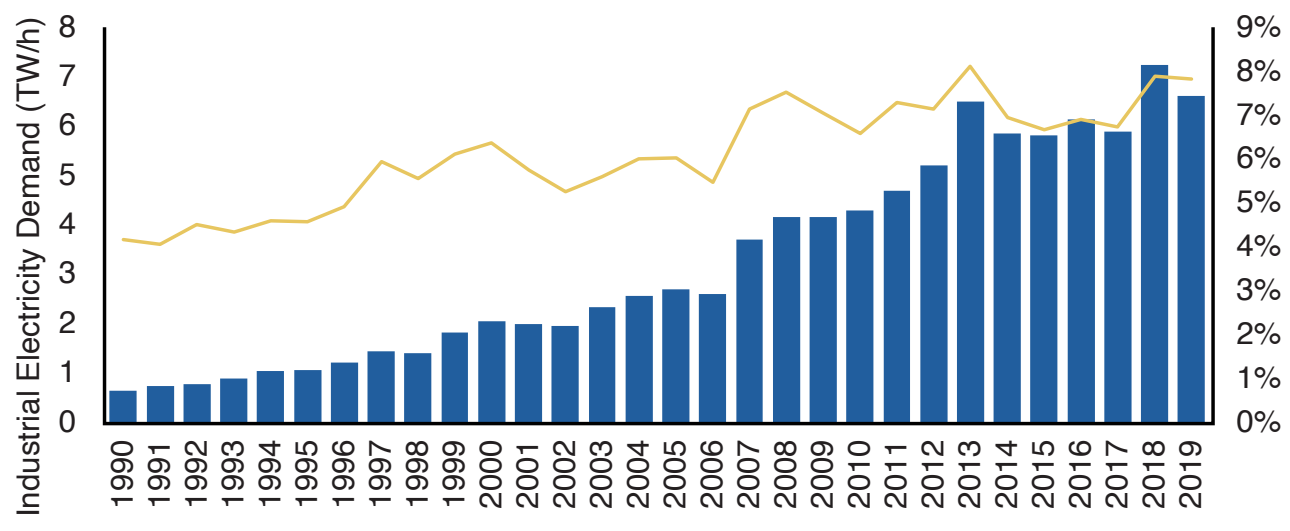

WOA Industrial Electricity

WOA Industrial Electricity share of Total Electricity

SOA

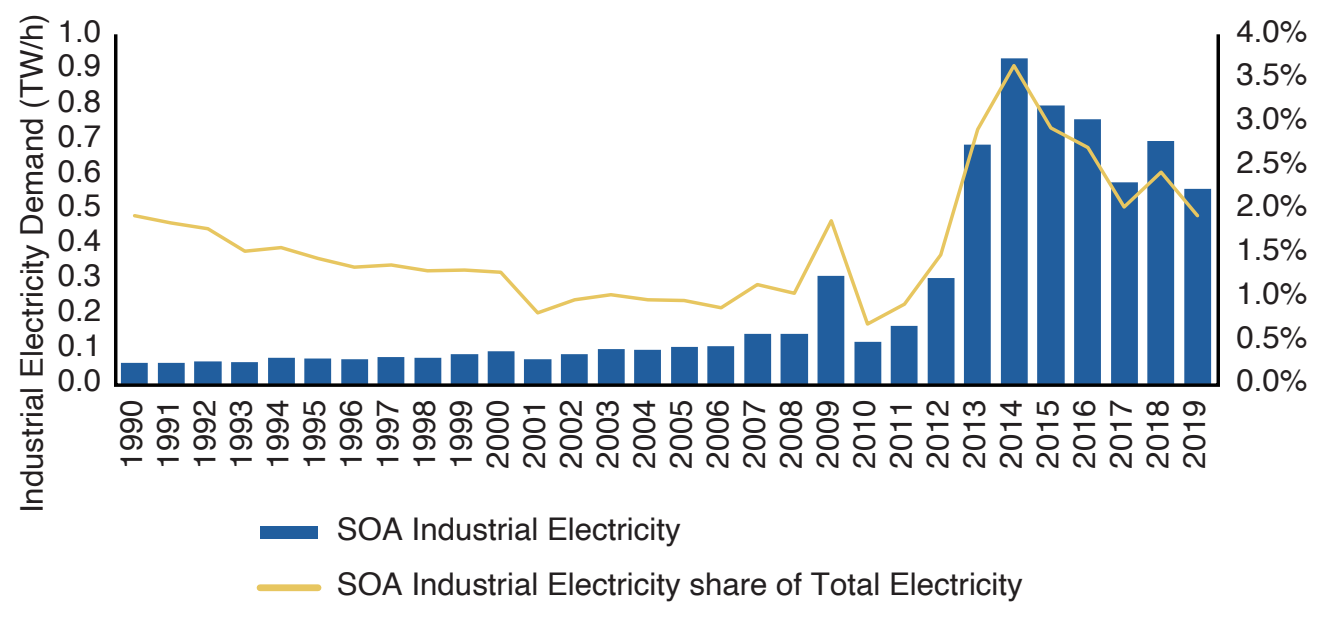

Source: SEC via SAMA 2020. 


\section{Empirical Estimation Results}

\subsection{Unit root test results}

Following the time series modeling routine, first the variables under investigation are tested for unit root properties using the ADF test. The results of the unit root exercises are presented in Table 4.

As Table 4 demonstrates, all the variables are integrated at the first order for all regions. Hence, one can test whether the region-specific variables share common trends.

\subsection{Cointegration test results}

After concluding the same order of integration, the variables are tested for shared common trends. The Nyblom and Harvey $(2000,2001)$ cointegration test is employed to reveal whether there are long-run co-movements. The rank of a matrix is equal to the number of linearly independent rows (columns) of that matrix, which in turn corresponds to the number of different cointegrating vectors or relationships. In addition, the rank of a matrix is equal to the number of eigenvalues that are statistically different than zero. Hence, the number of cointegrating vectors is the number of statistically non-zero eigenvalues. The cointegration test results are reported in Table 5. Each row corresponds to the eigenvalues, in descending order, for each region.

As seen in Table 5, in all four regions, the cointegration test concluded the existence of one cointegration relationship. Therefore, one can conclude there are long-run relationships among the variables.

Table 4. Summary of the unit root test findings.

De

\begin{tabular}{|c|c|c|c|c|c|c|c|c|c|}
\hline & level & & Differ & level & & differ & level & & differ \\
\hline & int & int\&tr & Int & int & int\&tr & int & int & int\&tr & int \\
\hline $\mathrm{COA}$ & -2.324 & 0.338 & $-7.999^{\star * \star}$ & -1.350 & $-3.262^{*}$ & $-6.455^{\star \star \star}$ & -1.509 & -1.809 & $-5.118^{\star * *}$ \\
\hline EOA & -1.262 & -2.940 & $-5.992^{\star \star \star}$ & & & & & & \\
\hline SOA & -0.425 & -2.295 & $-5.832^{\star \star \star}$ & & & & & & \\
\hline WOA & -1.174 & -2.700 & $-6.071^{* * *}$ & & & & & & \\
\hline
\end{tabular}

Notes: Income and price are the same for all regions; max lag set to 2 and the optimal lag is chosen based on the Bayesian

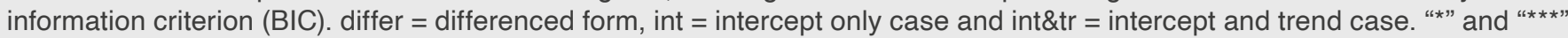
stand for rejection of null at the $10 \%$ and $1 \%$ significance levels, respectively.

Table 5. Cointegration test results.

\begin{tabular}{l|l|c|c} 
Region & \multicolumn{3}{|c}{ Eigenvalues } \\
\hline COA & $0.04515^{\mathrm{a}}$ & $1.084 \mathrm{e}-19$ & $-6.939 \mathrm{e}-18$ \\
\hline EOA & $0.01539^{\mathrm{a}}$ & $3.470 \mathrm{e}-18$ & $-1.735 \mathrm{e}-18$ \\
\hline SOA & $0.06578^{\mathrm{a}}$ & $3.469 \mathrm{e}-18$ & $-3.469 \mathrm{e}-18$ \\
\hline WOA & $0.00413^{\mathrm{a}}$ & $5.421 \mathrm{e}-19$ & $2.168 \mathrm{e}-19$ \\
\hline
\end{tabular}

Notes: "a" = statistically different than zero. 


\subsection{Long- and short-run estimation results}

After ensuring the existence of a unique cointegration relationship, we can estimate the relationship among the variables of interest by using the STSM approach. In line with the specification discussed in section 4.1, first the estimations are done using equation (2). For all regions, the regional population variable is found to be insignificant. The unresponsiveness of regional industrial electricity consumption to population can be explained by the features of industry in the different regions. For example, industry in the EOA and WOA regions is mainly export oriented. This might be the reason why the impacts of population on electricity consumption in these regions are insignificant. In addition to controlling for regional population size, to reveal other potential drivers of regional industrial electricity consumption, we also control for variables such as the price of heavy fuel oil (HFO) and crude oil for industry. The estimation results revealed that neither takes a role in shaping the regional industrial electricity demand for the period under investigation.
In addition, HFO and crude oil are not substantial substitutes for electricity in industrial use (see e.g., Steinbuks 2012). Hasanov (2021) discusses that, for Saudi Arabia, it is cost-effective to take electricity from the network rather than burning fuel or natural gas. Similar results were also obtained by Shirani-Fakhr, Khoshakhlagh, and Sharifi (2015) in the case of natural gas in Iran.

The long and short-run estimation results are given in Table 6. The detailed estimation results, as well as the results of the diagnostic tests, are provided in Table B1 in Appendix B. In the estimations considering the sample size, we use two lags as the maximum lag number for all variables and the final version is chosen based on the general to specific approach as well as comparing other model selection criteria. The estimation results revealed that price has a statistically significant negative impact in the long run in all regions, while in the short run, it is found that consumption is unresponsive to price in EOA and SOA. Income is also found to have a positive and statistically significant impact in all regions, in the short and long run.

Table 6. Long- and short-run elasticities.

\begin{tabular}{|c|c|c|c|c|}
\hline \multirow[b]{2}{*}{ Region } & \multicolumn{2}{|c|}{ Income } & \multicolumn{2}{|c|}{ Price } \\
\hline & Short run & Long run & Short run & Long run \\
\hline COA & $0.449^{\star \star}$ & $0.449^{\star \star}$ & $-0.101^{\star *}$ & $-0.178^{\star \star}$ \\
\hline EOA & $0.523^{\star \star}$ & $0.523^{\star \star}$ & - & $-0.021^{\star \star} a /-0.060^{\star *} b$ \\
\hline SOA & $1.064^{*}$ & $1.064^{*}$ & - & $-0.249^{*}$ to $-0.147^{*}$ \\
\hline WOA & $0.562^{* * *}$ & $0.562^{* \star *}$ & $-0.122^{\star \star}$ & $-0.122^{\star *}$ \\
\hline
\end{tabular}

Notes: “***", "**” and "*” indicate statistical significance of a coefficient at the $1 \%, 5 \%$ and $10 \%$ significance levels, respectively. $a=$ coefficient before 2009 (including 2009) and b = coefficient after 2010 (including 2010). 


\section{Empirical Estimation Results}

As Table 6 demonstrates, industrial electricity is largely explained by income levels, which vary by region. That is, the income elasticity is higher in low income regions and smaller in richer ones, based on the regional GDPs used in Lopez-Ruiz, Blazquez, and Hasanov (2019). ${ }^{2}$ Based on Lopez-Ruiz, Blazquez, and Hasanov (2019), in total terms, the order of regions according to GDP is as follows: COA, EOA, WOA and SOA. The price and income elasticities are also tested for potential time-varying nature for all regions. The income elasticity is found to be constant in all regions for the investigation period, whereas the coefficient of the price variable is found to be time varying in the case of EOA and SOA. Hence, we only discuss the price parameter in these two regions. Treating the coefficient of price for EOA in the STSM framework first as a random walk and second as a smooth spline produces the results depicted in Figure 6. As seen in Figure 6, the coefficient seems to demonstrate a time-varying nature. Although the coefficient is statistically insignificant and even positive in some periods, the message taken from Figure 6 is that it is not constant over time. To have an initial idea of the coefficient's different behavior for different time intervals, see the periods separated by vertical lines in the figure crossing the coefficient.

Figure 6. Varying price coefficient with two standard error bands, STSM output: A) random walk and B) smooth spline.
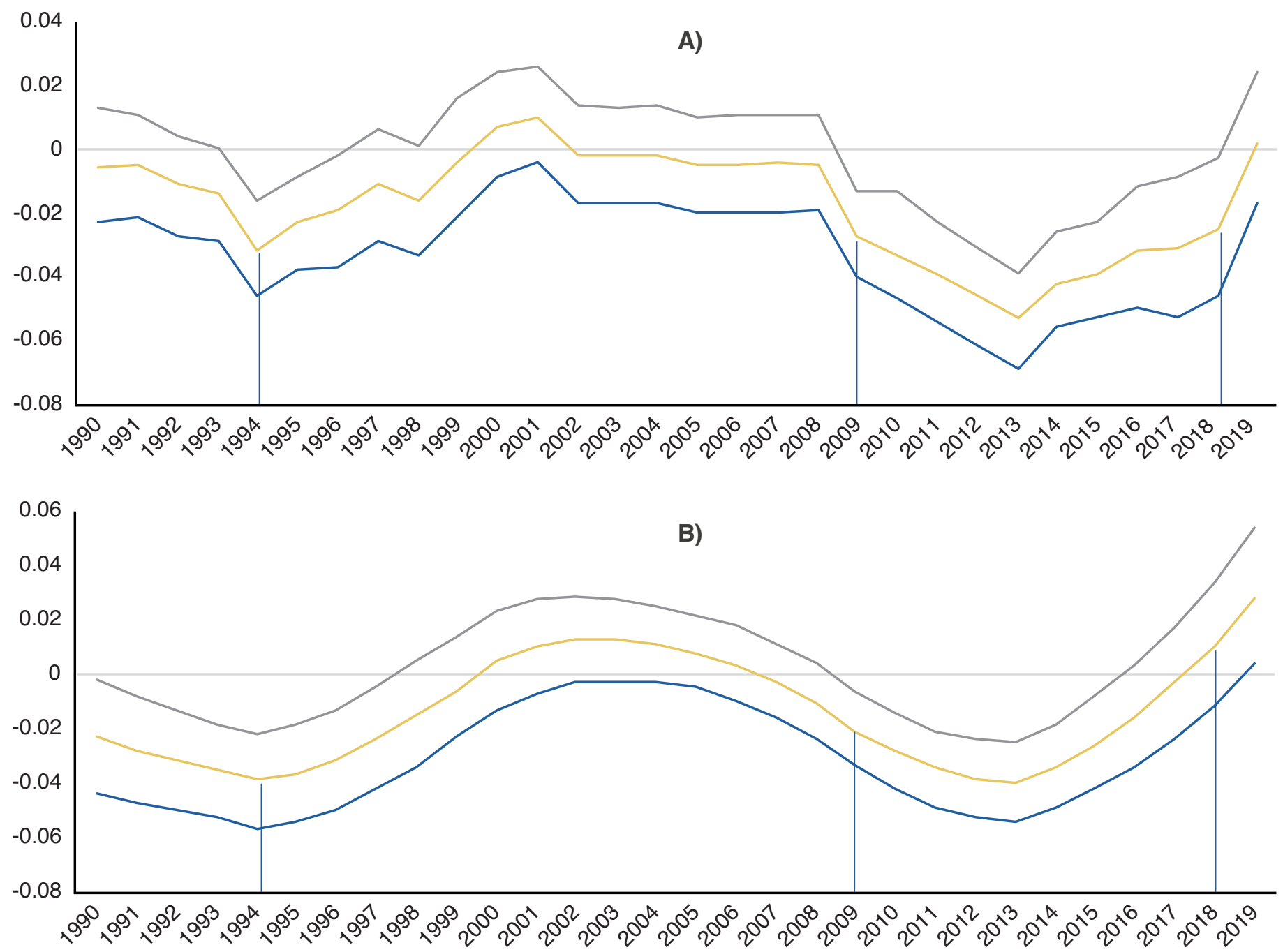

Source: Estimation results. 
To test whether the price elasticity is indeed time varying, we further employ another technique that allows us to treat coefficients as time varying. Namely, the MIS (Ericsson 2012; Castle, Hendry, and Martinez 2017; Castle and Hendry 2019) approach is used. First, we employ the MIS approach to reveal whether the intervals of price elasticity change the behavior. In line with the findings of the STSM approach, the MIS approach concluded that the coefficient of price is -0.02 before 2010 and -0.06 after 2010 , both being statistically significant. Hence, we find that the coefficient of price demonstrates a varying nature, differing before and after 2010. For the period before 1994, the changes in the elasticity are trivial. Thus, we treat it the same as the period until 2010. In addition, the change after 2018 is found to be insignificant. The insignificance of the change post-2018 might be because we have only two observations, which might not be sufficient to reveal variation in the change. As a final step to unify the results in terms of applied technique, we combine the STSM and MIS approaches. In other words, the reported results are found using the STSM approach, where we add the price variable multiplied by the step dummy for 2009 (1 up until 2009 and 0 afterward).

In the case of SOA, again the coefficient of price is treated as time varying, random walk and the result is presented in Figure 7. As seen in Figure 7, the coefficient demonstrates that the varying nature is statistically significant for the entire period. In terms of magnitude, the price elasticity ranges from -0.249 to -0.147 , taking the biggest value (in absolute term) in 2015.

Figure 7. Varying price coefficient with one standard error bands, STSM output.

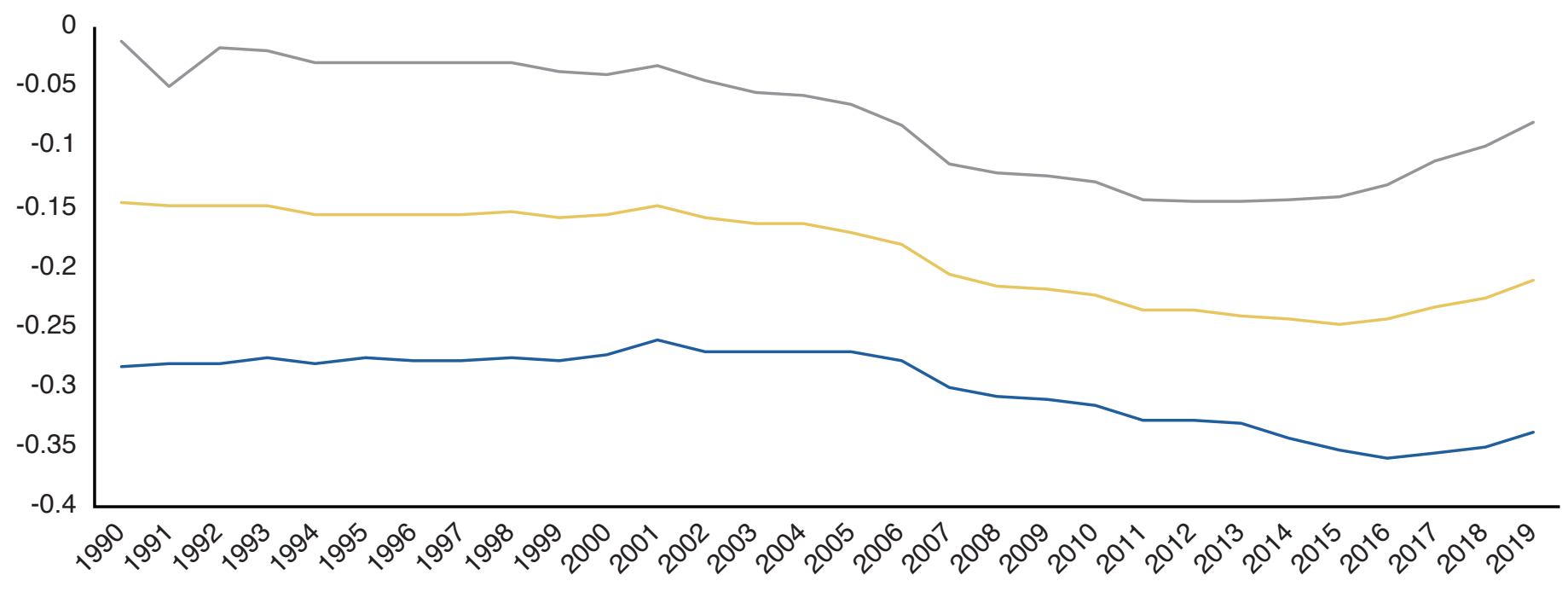

Source: Estimation results. 


\section{Empirical Estimation Results}

The estimation results (see Table B1 in Appendix B) The UEDTs determined through from empirical confirm that the speed of the adjustment coefficients estimations are given in Figure 8.

for all regions lies within the expected borders and

are statistically significant.

Figure 8. Estimated region-specific UEDTs.
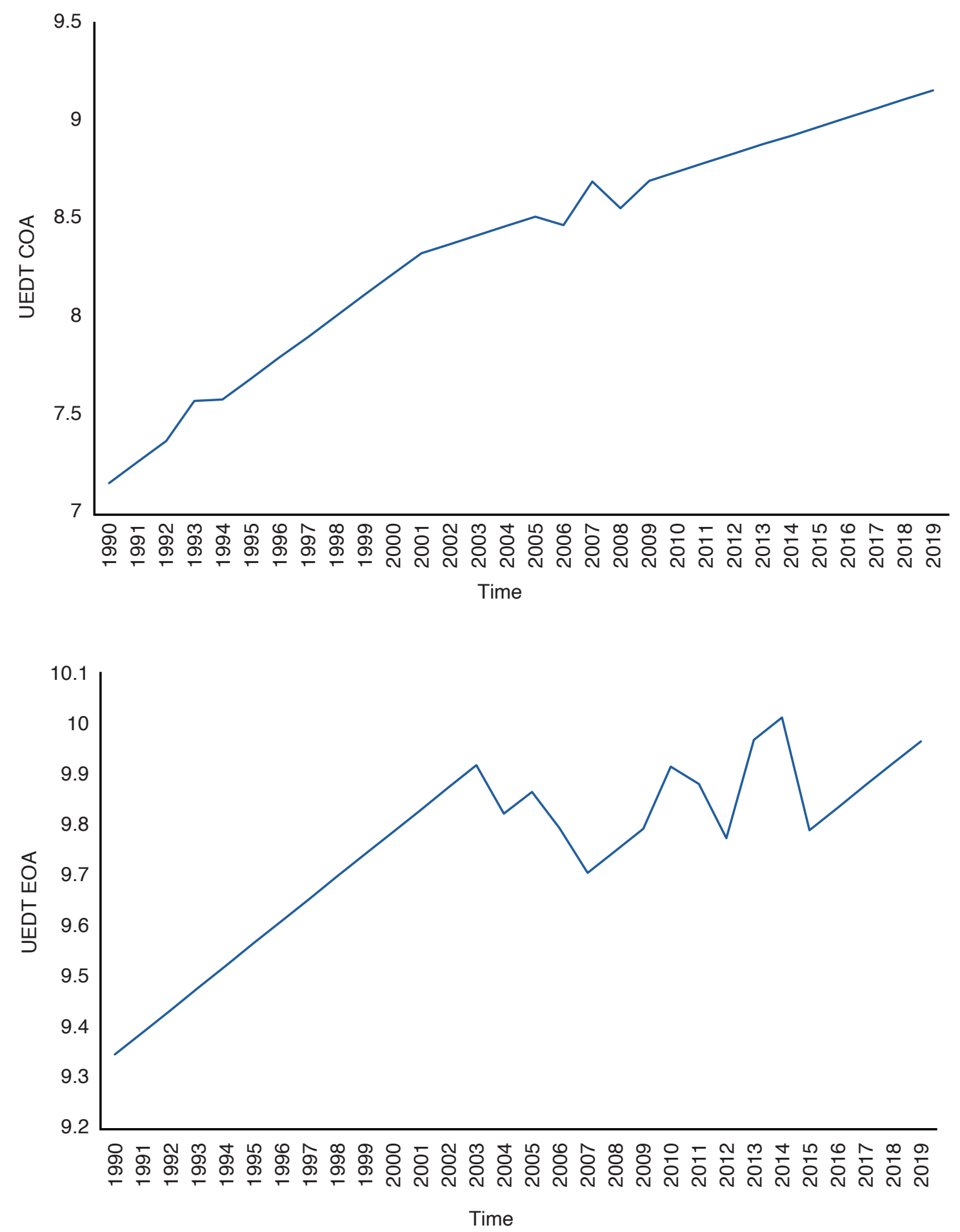

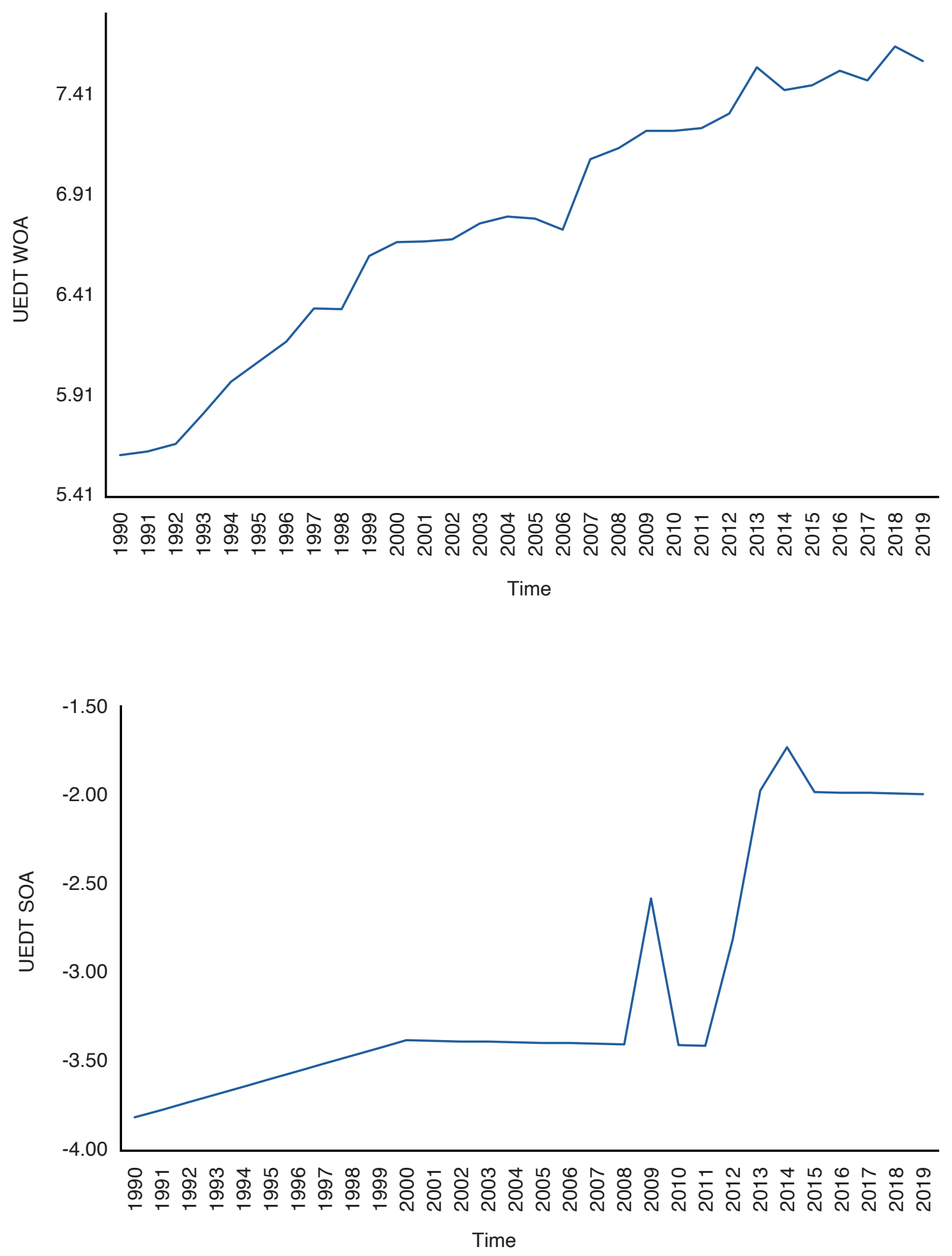

Source: Estimation results. 


\section{Discussion of the Findings}

$\mathrm{T}$ The discovery of drivers of industrial electricity consumption at the regional level revealed that the consumption responses to these drivers differ across regions. The income responses of industrial electricity consumption are found to be higher in relatively low income regions and smaller in richer ones. These findings are in line with economic intuition and region-specific features. Intuitively, in a state/region where the establishment of the industrial sector has not reached a mature stage and is mainly reliant on government-backed investments, the region's economic activities and, consequently, electricity consumption will be shaped depending on income level. Further, some will be affected by lags. It is important to note that government investments, prior to the launch of Vision 2030, were susceptible to oil price volatility because the oil share of revenues was historically much higher (SAMA 2019; Durand-Lasserve and Karanfil 2021).

Regarding the regions of the Kingdom, as discussed in section 2 , the SOA consumes only around $1 \%$ of total industrial electricity consumption. In addition, based on historical data (SEC via SAMA 2019), the SOA has witnessed enormous changes in industrial electricity consumption. Specifically, it was $117 \%$ in $2009,-61 \%$ in $2010,38 \%$ in $2011,82 \%$ in 2012, 126\% in 2013 and $36 \%$ in $2014-56 \%$ per annum during 2009-2014. These facts show the substantial developments in the region in terms of industrial sector, which is mainly based on huge government-initiated projects rather than regionbased initiatives (see Table 3). This can also be observed from the fact that the 2016 electricity price increase and temporary 'decline' in government-led projects highly affected the SOA region $(-5.2 \%)$, while in other regions the growth was positive. It seems that when industry-related projects are supported by government, production activities, and consequently industrial electricity consumption, go up substantially. When support/activities temporarily decelerate, consumption declines. The electricity consumption in the SOA's industrial sector was also highly affected in 2015 and 2019, with significant oil price drops: -14\% in 2015 and $-20 \%$ in 2019 (Figure 4). These facts show the high sensitivity of the region's economic/industrial activities to the income path of government-backed projects. In this regard, having higher income elasticities for relatively low income, or not well industrialized, regions that follow market fundamentals is rational. Compared with the results of previous studies, which only considered overall industrial electricity consumption, not regional consumption, the range for Saudi-specific long-run income elasticities is $0.20-0.50$ (see Table 2), while our region-specific numbers range from 0.45 to 1.06 . The two intervals overlap. In other words, our findings are in line with Saudi Arabiaspecific results in terms of magnitude. Only two studies, Hasanov (2019) and Hasanov et al. (2020) have investigated the short-run effects. Hasanov (2019) found the short-run income elasticity to be 0.35, while Hasanov et al. (2020) concluded the impact was insignificant. However, we found it to be significant in all regions. The analysis of the growth path of industrial electricity consumption across regions show that the SOA and WOA are more sensitive to income changes, while it is less so for the COA and EOA. Further investigation shows that the COA region has witnessed positive growth in industrial electricity consumption since 2009 at 5.5\% per annum. It was not impacted by the $49 \%$ decline in oil prices in 2015, 2016 electricity price increase (almost 30\%) and 2019 oil price drop (9\%), realizing a $6 \%, 4 \%$ and $8 \%$ increase in industrial electricity consumption in those years, respectively. These facts allow us to conclude that industrial activities are more diversified in the COA region, compared with the other regions. The EOA, mainly focused on oil-related activities, also seems to be sensitive to substantial oil price drops as it declined by $17 \%$ in 
2015 and 4\% in 2019 with historical oil price drops. In 2019, the oil price drop was followed by a decline/ cut in oil production policy, resulting in shrinkage in oil-related activities. This, in turn, meant a decline in industrial electricity consumption. In general, oil-related events, oil prices and oil production have played a substantial role in industrial activities. Thus, industrial electricity consumption is impacted mainly through income channel. These impacts are higher in the EOA and SOA.

In terms of the price responses of industrial electricity consumption, the long-run price elasticities are relatively closer to each other in the COA, SOA and WOA. The smaller price response in the EOA region might be due to the fact that industrial activities in these regions are more fuel intensive, not electricity intensive. The highest long-run response is found in the SOA. This is owing mainly to micro-sized industrial firms (91\%) focused on manufacturing food products and fabricated metal products. These firms are sensitive to price changes. The second highest long-run price elasticity is found in the COA. The COA is mainly concentrated on industries such as the manufacture of paper products, computers, electronics and optical products, electronic equipment, motor vehicles, trailers and semi-trailers and other transport equipment. All of these are more electricity intensive. Compared with the EOA region, the WOA has a more diverse industrial shape, with food manufacturing, a high electricity-intensive sector, accounting for a substantial share, alongside the manufacture of water supply industries. Compared with previous studies, our long-run price elasticities are close to those of Hasanov (2019), who investigated total industrial electricity consumption. Small price elasticities for the regions are expected because, in nominal terms, from 2002 to 2019 there were three cases where prices saw a change. Namely, in 2010 there was an adjustment to tariffs, in 2016 there was a $20 \%$ increase and in 2018 there was a $5 \%$ VAT increase.

To uncover whether the coefficients/elasticities demonstrate varying nature over time, all the parameters for all regions are tested using the STSM and MIS approaches. The coefficient of price in the case of the EOA, which accounts for $72 \%$ of total industrial electricity consumption, is found to reveal a varying nature, differing before and after 2010. The coefficient, the response of industrial electricity demand to price, is -0.02 before 2010 and -0.06 after that period. The increased response after 2010 can be explained by factors such as the policies pursued by the established Saudi Energy Efficiency Center (SEEC) in 2010, which have also contributed to the efficiency gains captured by the stochastic demand trend. The SEEC target was to achieve the lowest levels of energy consumption. In 2010 there was an adjustment to tariffs for industrial electricity users. The next year, the energy management program of Saudi Aramco, which is in the EOA, attained an energy savings of about 10,000 barrels of oil equivalent per day (Nachet and Aoun 2015). The realized policies for efficient use of energy in parallel to social awareness targets resulted in substantial behavioral change in the price response starting in 2010. Similarly, in the SOA region, the applied technique concluded varying price elasticity, ranging from -0.25 to -0.15 . The impact of important economic events is obvious from the behavior of the SOA price elasticity as well. The 2008 global financial crisis caused the price elasticity to decline substantially, which in turn caused a decline in electricity demand. The 2010 price adjustment and efficiency policies also resulted in a price response decline. The 2014 oil price drop caused a sharp decline in price elasticity. Historically the highest price response $(-0.25)$ in the SOA occurred in 2015, when the highest drop in oil price $(49 \%)$ for the study period occurred. 


\section{Discussion of the Findings}

The second highest price elasticity value took place in 2016, when the industrial electricity prices increased by $20 \%$. Combining the finding of varying response of industrial electricity consumption to price in the two regions, one can say that the response of industrial electricity consumption to price is small. However, it can be used as a policy tool in coordination with other awareness targets. The short-run price elasticity is found to be statistically significant only in the COA and WOA. Our interpretation of the unresponsiveness to price change in the other two regions is the fact that in the EOA and SOA, the industrial sector is more government supported. This support may delay the actual economic impact.

The income elasticity in all regions is found to be the same in the long and short run from the STSM estimations. One can argue that this finding is a statistical outcome rather than an economic one as the lagged terms of electricity consumption and income are insignificant and excluded from the final model (see Appendix B). As a result, the calculations of the long-run elasticities yield the same values as the short-run ones. To address this concern, we use another estimation method called the time-varying cointegration coefficient (TVCC) approach developed by Park and Hahn (1999). It also allows the intercept term, among others, to be time varying in the estimations. We applied this method to the WOA region as, in addition to income elasticity, the price elasticity is also the same in the long and short run. The details of the estimations are reported in Appendix C. The results from the TVCC approach indicate that the long- and short-run income elasticities are 0.650 and 0.673 , respectively. In contrast, the numerical values for the long- and short-run price elasticities are -0.191 and -0.185 , respectively. The estimated numerical values of the elasticities are quite close to each other. Additionally, we perform the chi-squared test to check whether they can be statistically different from each other; the results show that they are equal to each other (see Table C3). It appears that the results from the TVCC method yield similar results to those from the STSM method, although the numerical values for the income and price elasticities are different (i.e., 0.650 versus 0.562 and -0.191 versus -0.122). Overall, the estimation results from the two methods show that the long- and short-run elasticities are quite close to each other. Note that Alarenan, Gasim, and Hunt (2020) also find the short- and long-run income elasticities to be the same in the case of industrial energy consumption in Saudi Arabia. These findings can be explained by the nature of the Saudi industry (such as efficiency, productivity and competitiveness). For example, although efficiency in industrial electricity demand in each region and thus for the industry sector as a whole improved, it was not substantial over the period under consideration, as discussed below.

As discussed in section 4, the UEDT can be interpreted as a measure of energy efficiency, which, among other exogenous factors, impacts the demand. While in all regions the UEDT is generally increasing, the slope of the stochastic trend becomes less steep, meaning that its growth rate is slowing down over time. This might suggest that some efficiency improvements have occurred in the industrial sector, although they do not appear to be substantial. These efficiency improvements accelerated after the establishment of SEEC. Alarenan, Gasim, and Hunt (2020) also reveal that energy efficiency policies reduced industrial energy consumption in the Kingdom after 2010.

The speed of adjustment (SoA) coefficients (Table B1 in Appendix) enables us to conclude that, in all the regions, the short-run deviations can be corrected to a long-run equilibrium within a year. The coefficients are the same for each region; that 
is, they are -1 . We have two main explanations for this result. First, our income measure is the same in all four equations for industrial electricity demand in each region, that is, the total value added of the industrial sector. Moreover, the price measure is the same for all equations because there is no regional price discrimination in Saudi Arabia. The income and price measures we use to analyze industrial electricity demand appear to be the same across regions. Second, historically, the industry sector in Saudi Arabia has had significant support from the government. In addition, this support continues through different support policies as "A set of procedures are being developed to support sector players and reduce energy reform impact..." (NIDLP 2019). From this perspective, it can be the case that industrial electricity demand adjusts its long-run path to the existence of change faster because of the government support policies in all regions. Third, for the SoA coefficient in the WOA region, the estimation results from the STSM and TVCC methods yield very close numerical values (-1 versus -1.05). 


\section{Forecasting Regional Industrial Electricity Demand}

In this section, we present forecast assumptions and the results of forecasting exercises. Using the estimated regional demand equations, we forecasted the industrial electricity consumption for the next 11 years, namely the 2020 to 2030 period. Considering the substantial changes in overall economy, including the industrial sector, in 2019 caused by oil price fluctuations and in 2020 by the COVID-19 pandemic, the forecasting exercises require further caution. To avoid/minimize the potential forecast failure, first the model was estimated up until 2018 and the 2019 demand values were forecasted. Then, the difference between the 2019 actual and forecast values were used to adjust the 2020 forecasts, according to the so-called intercept-correction approach (see, e.g., Clements and Hendry 1998). Based on forecasts for the Saudi economy (e.g., OE 2020 December Report for Saudi Arabia) in 2021, the economy is expected to grow at a rate similar to 2018, both in terms of overall GDP level and the industrial sector. Hence, the correction is only applied to 2020 values.

\subsection{Forecast assumptions}

We now discuss the assumptions of the forecasting exercises. We employ two scenarios, called 'business as usual' (Bau) and 'low scenario' (Low). In the Bau case, we assume that prices over the forecast horizon will be at the same level as in 2019 . For 2020 , the price increased by $10 \%$, considering the July 1, $202010 \%$ additional VAT increase and the $5 \%$ VAT increase after January 1, 2018. As the 2020 VAT was implemented starting on July 1 , we compare the industrial activity level for the first and second quarters of 2020 with recent years. Thus, it is rational to assume that the new total 15\% VAT, effective after the first half of the year, will result in a $10 \%$ price increase in 2020. During 2021-2030, the 2017 prices increased by $15 \%$, considering the overall VAT impact.

The Low scenario is set so that the industrial electricity price reaches the international price level in 2025. As an international price level, we employed the U.S. average price of electricity for the industrial sector for the 2008 to 2017 period, which was about $\$ 0.07 / \mathrm{kWh}$ or $0.26 \mathrm{SAR} / \mathrm{KWh}$. This assumption is made to discover the industrial electricity demand path, both regionally and for the Kingdom overall, in a case in which Saudi Vision 2030 is realized. This vision puts certain targets for rational and efficient use of energy (e.g., FBP 2019).

The growth rate assumptions for industrial GVA are taken from simulation runs of the macroeconometric model (Hasanov et al. 2020). Because the focus is to see the price impact on demand, we assume that for the forecast horizon the UEDT of the processes follows the same trajectory, the last historical value fixed for the forecast horizon.

\subsection{Forecasting results}

Using the estimated region-specific demand equations and based on the assumptions presented above, the demand forecasts are given in Figure 9. We present actual 2019 values for comparison purposes. The results of the forecasting exercises show that for the 2020-2030 forecast horizon, on average, industrial electricity demand is expected to grow by $5.5 \%, 5.6 \%, 2.3 \%$ and $0.75 \%$ per annum in the COA, EOA, SOA and WOA regions, under the Bau scenario case. In the Low scenario, these numbers are $4.8 \%, 5.5 \%, 1.4 \%$ and $0.23 \%$ for the COA, EOA, SOA and WOA regions, respectively. In COA and EOA, according to both scenarios, industry consumption of electricity will almost double 
compared with 2019 consumption levels. In the other two regions the change is not so substantial. Only the WOA region is expected to see negative growth in 2020. The historical behavior of industrial electricity demand shows that the WOA was the only region negatively impacted by events such as the 2009 economic slowdown following the financial crisis and the 2014 oil price drop. In addition, it was the second most impacted region by the 2019 oil price fluctuations, after the SOA. Considering these points, it seems reasonable for the WOA to see negative growth in 2020 .
Numerically, for the Low scenario, the 2030 demand forecasts are 11.6 TWh, 63.5 TWh, 0.6 TWh and 6.8 TWh for the COA, EOA, SOA and WOA, respectively. Considering the region-specific forecasts, the total demand forecast values can be derived to be 82.5 TWh for 2030. The corresponding numbers for the Bau scenario are 12.5 TWh, 65.5 TWh, 0.7 TWh and 7.2 TWh for the regions and 85.8 for the overall Kingdom.

Figure 9. Forecasted values for industrial electricity consumption, TWh.

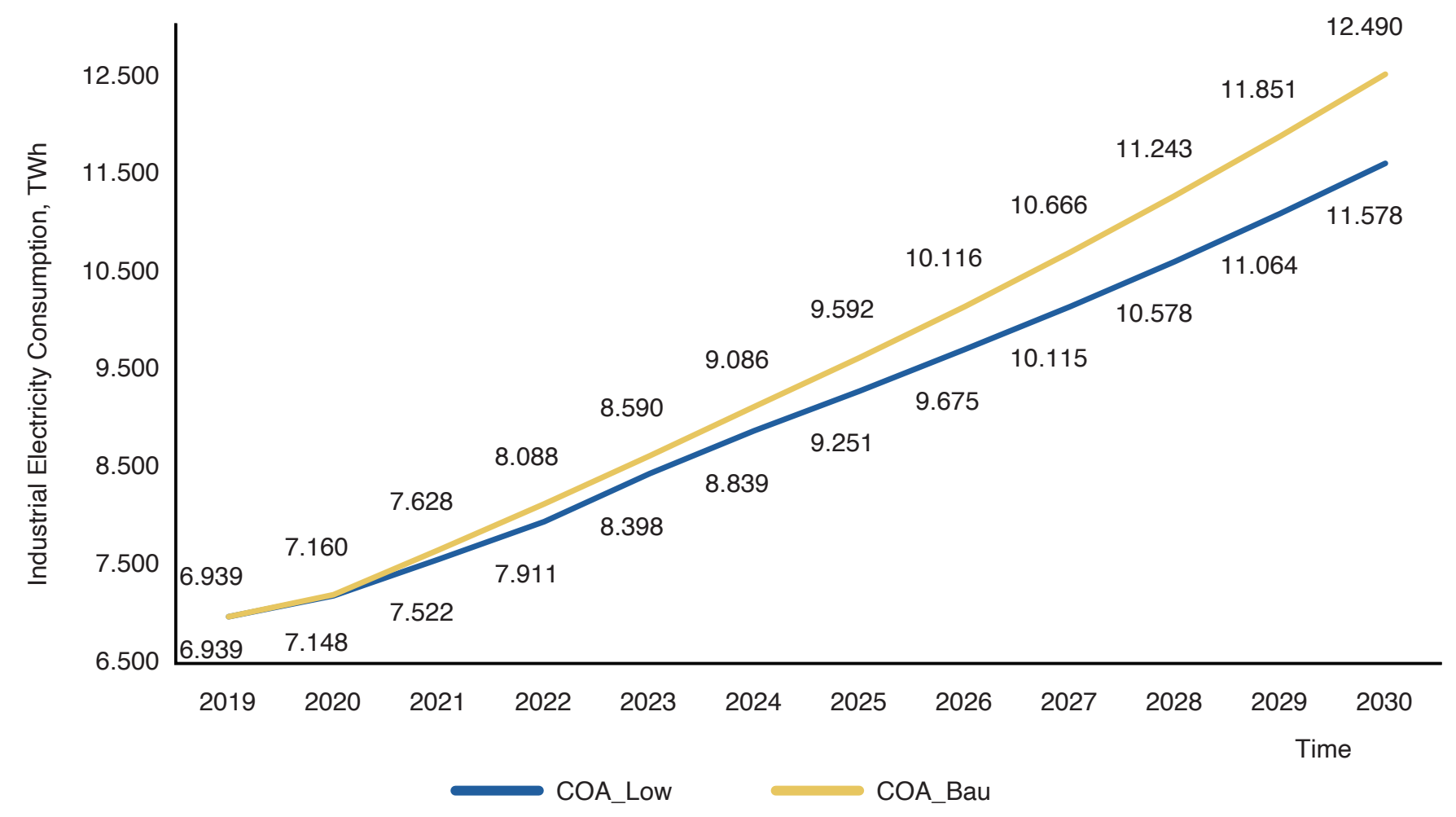




\section{Forecasting Regional Industrial Electricity Demand}
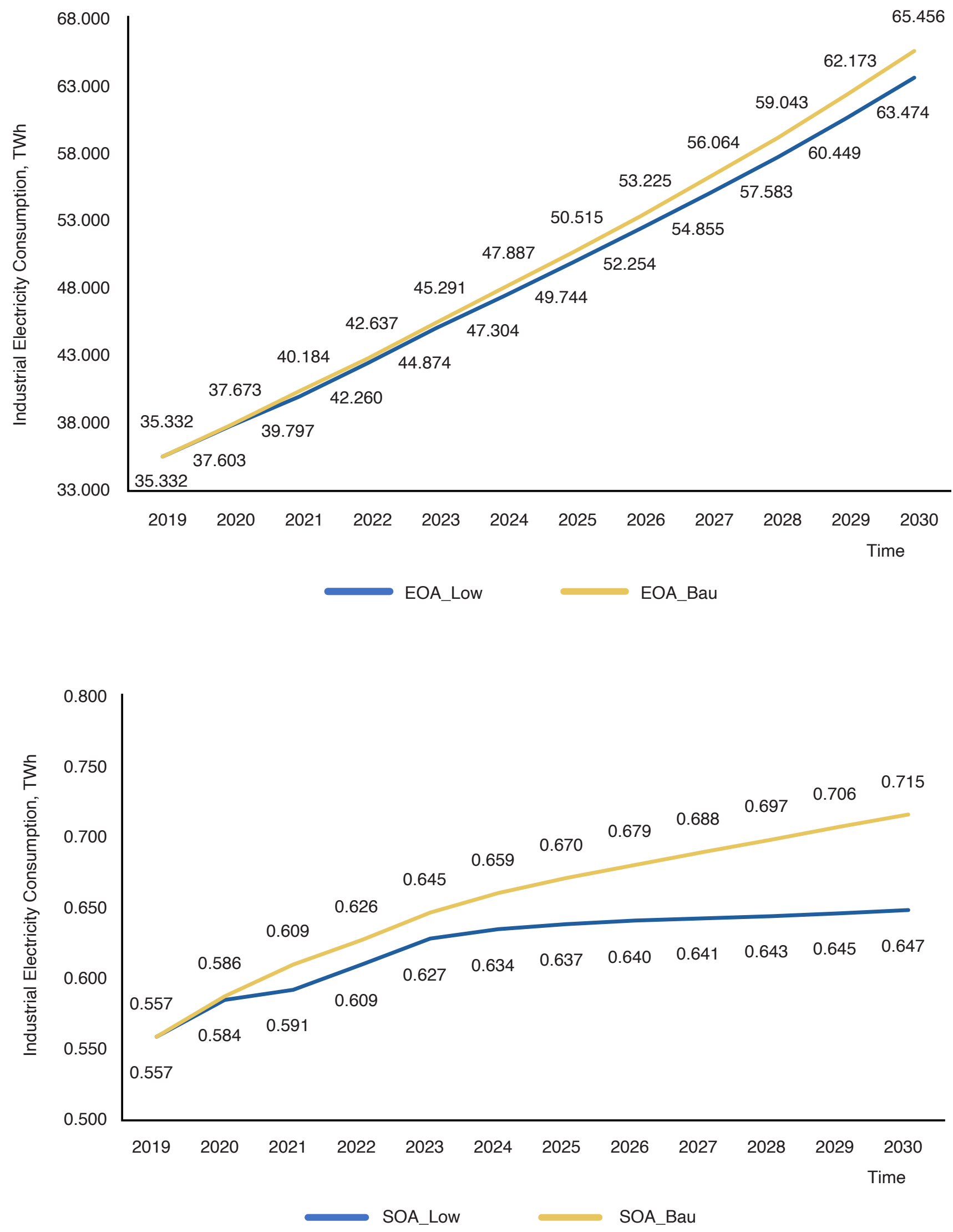

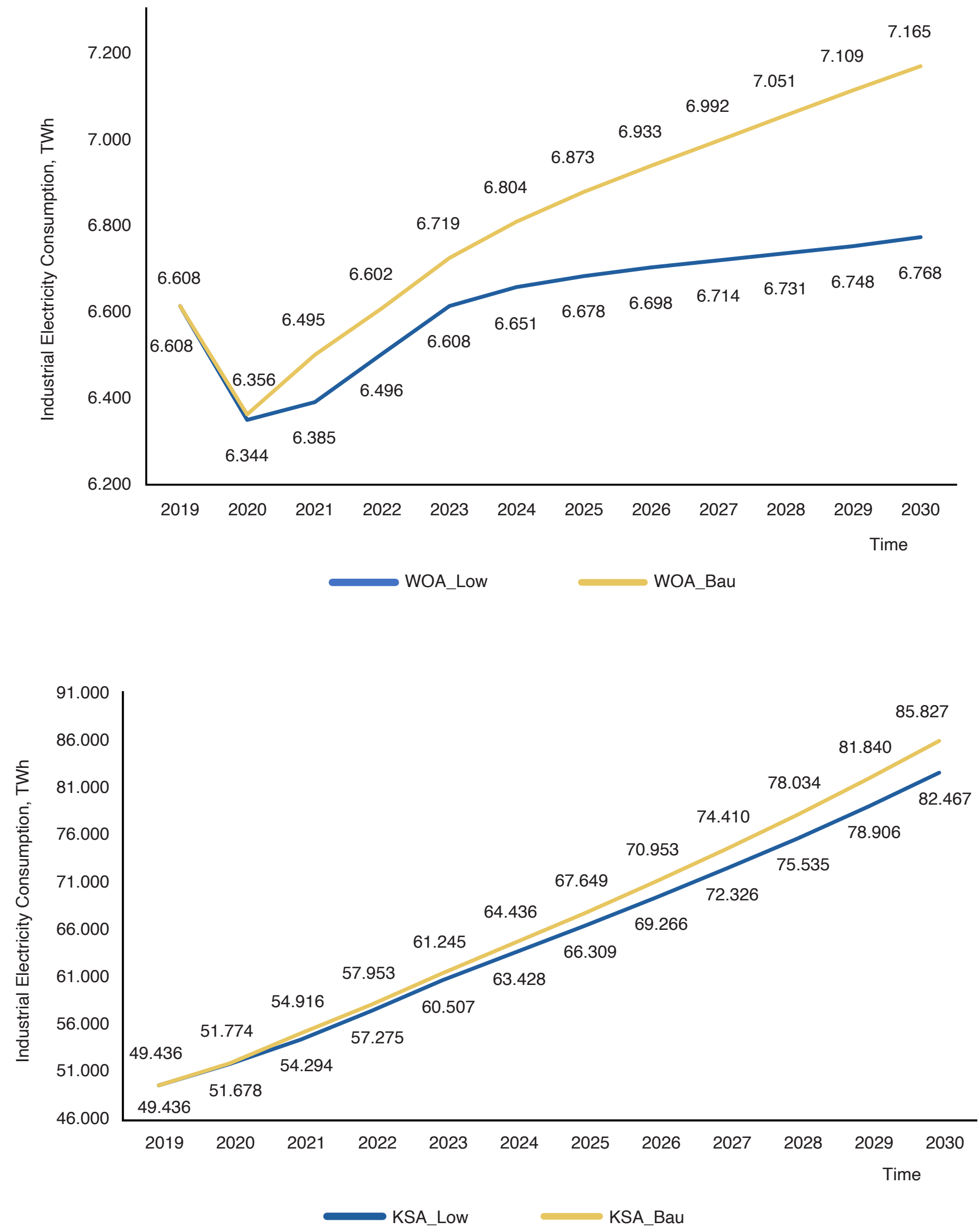
Using the obtained region-specific demand forecast, we also calculate peak demand values for the forecast horizon. In the peak demand exercises, we use $83 \%$ as a load factor for 2020 , which is the historical average of load factors during 2012-2019. As the aim is to improve the load factor, we increase the 2020 value by $0.22 \%$ per annum (historical average growth rate of peak load for 2012-2019), which yields $85 \%$ in 2030 . The obtained peak demand values are presented in Table 7. As shown in Table 7, in 2030 the Kingdom-wide peak demand for electricity in industry in the Low scenario is 10.85 gigawatts (GW), while in the Bau scenario it is 11.29 GW. The regional peak demand values vary according to their demand requirements.

Table 7. Peak demand, in GW.

\begin{tabular}{|c|c|c|c|c|c|c|c|c|c|c|}
\hline & $\begin{array}{l}\text { COA_ }_{-} \\
\text {Low }\end{array}$ & COA_Bau & EOA_Low & EOA_Bau & SOA_Low & SOA_Bau & $\begin{array}{c}\text { WOA_ } \\
\text { Low }\end{array}$ & $\begin{array}{c}\text { WOA_- } \\
\text { Bau }\end{array}$ & KSA_Low & KSA_Bau \\
\hline 2020 & 0.98 & 0.98 & 5.17 & 5.18 & 0.08 & 0.08 & 0.87 & 0.87 & 6.96 & 6.98 \\
\hline 2021 & 1.03 & 1.05 & 5.46 & 5.51 & 0.08 & 0.08 & 0.88 & 0.89 & 7.30 & 7.38 \\
\hline 2022 & 1.08 & 1.11 & 5.79 & 5.84 & 0.08 & 0.09 & 0.89 & 0.90 & 7.68 & 7.77 \\
\hline 2023 & 1.15 & 1.17 & 6.13 & 6.19 & 0.09 & 0.09 & 0.90 & 0.92 & 8.09 & 8.19 \\
\hline 2024 & 1.20 & 1.24 & 6.45 & 6.53 & 0.09 & 0.09 & 0.91 & 0.93 & 8.46 & 8.60 \\
\hline 2025 & 1.26 & 1.30 & 6.77 & 6.87 & 0.09 & 0.09 & 0.91 & 0.93 & 8.83 & 9.00 \\
\hline 2026 & 1.31 & 1.37 & 7.09 & 7.22 & 0.09 & 0.09 & 0.91 & 0.94 & 9.20 & 9.42 \\
\hline 2027 & 1.37 & 1.44 & 7.43 & 7.59 & 0.09 & 0.09 & 0.91 & 0.95 & 9.58 & 9.86 \\
\hline 2028 & 1.43 & 1.52 & 7.78 & 7.98 & 0.09 & 0.09 & 0.91 & 0.95 & 9.98 & 10.31 \\
\hline 2029 & 1.49 & 1.60 & 8.15 & 8.38 & 0.09 & 0.10 & 0.91 & 0.96 & 10.40 & 10.79 \\
\hline 2030 & 1.56 & 1.68 & 8.54 & 8.80 & 0.09 & 0.10 & 0.91 & 0.96 & 10.85 & 11.29 \\
\hline
\end{tabular}




\section{Conclusion and Policy Implications}

his study investigates the behavior of industrial-sector electricity consumption in Saudi Arabia. It is the first study to focus on the issue at the disaggregated regional industrial electricity level. Using data spanning from 1990 to 2019, the STSM approach is applied to the relationship between industrial electricity consumption and its potential drivers. In the estimations, industrial value added, electricity price for industry, domestic oil price, price of HFO and region-specific population size are used as potential drivers. The empirical estimation results revealed that, at the regional level, only industrial value added and price of electricity drive electricity consumption in the industrial sector. It is found that the impact of income on electricity consumption varies depending on the region's development/industrialization level. The responses of electricity consumption to income and price are similar in the $\mathrm{COA}$ and EOA regions as they are more industrialized and settled. They are also quite close to each other in the SOA and WOA regions, which are relatively less developed compared with the other two regions. It is also found that there have been slight efficiency improvements in energy consumption for industrial activities in all regions in recent years. Based on statistical information, it is observed that in the SOA region, the majority $(90 \%)$ of industrial firms are small firms, employing fewer than five employees. These small firms are, by nature, expected to be more sensitive to income and price fluctuations, which have been happening since the 2008 international financial crisis and have accelerated after 2014 with the oil price drop. In this regard, one alternative solution to minimize this dependence might be establishing joint or bigger firms. Another alternative suggestion is rental of existing firms or lands and establishing entities that are sized consistent with the NIDLIP's small- and medium-sized enterprise and cluster development component, which will benefit field/landowners and new bigger firms. The government's policy to support and develop the industrial sector played a significant role in shaping the sector. Initiatives such as NIDLIP aim to support the industries impacted by the ongoing energy price reforms in addition to supporting investment, productivity and energy efficiency.

The estimation results reveal that in the biggest consumer region, the EOA ( $72 \%$ of total industrial electricity consumption), the demand response to price demonstrated varying nature, differing before and after 2010. The response increased substantially after 2010 , a result of the policies implemented by the SEEC, among other factors, which began that year. The price response was found to be time varying in the smallest consumer region, the SOA, as well. It was mainly impacted by the obvious economic events, such as the 2008 financial crisis, 2010 price adjustment, 2015 significant drop in oil price and 2016 electricity price increase. The finding of the varying responses of consumption to price allows us to conclude that electricity price for industrial users can be used as a policy tool to reach rational and efficient use of energy, although the response itself is small. Therefore, the finding encourages policymakers to use electricity pricing as a policy tool along with relevant social awareness targets.

The demand for electricity in industry witnessed in 2015 resulted from the substantial oil price drop and in 2019, which again had massive oil price fluctuations, huge declines were seen. ${ }^{3}$ Considering the negative consequences of the COVID-19 pandemic on the overall economy, it is also likely we will see a decline in industrial electricity demand caused by different factors, such as lockdown effects. Hence, it is important to have demand forecasts for the next few years for decision-makers to ground their policy decisions. Considering this importance, the study also made forecasts for the 
2020 to 2030 period based on certain assumptions. The demand forecasting exercises resulted in the following 2030 demand forecasts: In the Low scenario, the forecasts are 11.6 TWh, 63.5 TWh, 0.6 and 6.8 TWh for the COA, EOA, SOA and WOA, respectively. While in the Bau case, these numbers are 12.5 TWh, 65.5 TWh, 0.7 TWh and 7.2 TWh, accordingly. Using the demand forecasts, we calculated the region-specific peak demand values. The obtained regional peak demand values vary according to their demand requirements. The results show that in 2030, the peak demand in the Low scenario is $10.85 \mathrm{GW}$, while in the Bau scenario, it is $11.29 \mathrm{GW}$ for total industrial electricity use in the Kingdom.

Considering current policy implementations such as the ongoing EPR, oil price fluctuations and COVID-19-related impacts, the forecasts can be useful for setting relevant policies. In addition, the peak load values can be used by policymakers to gain a broader picture of the potential supply of electricity needed for the industrial sector.
This study explored industrial electricity consumption by modeling it at the regional level. To obtain a more comprehensive picture, there is a need for further future research. In other words, electricity demand modeling for the commercial, agricultural, public and other sectors at the regional level is a potential direction for future research. In addition to providing insight on regional electrical consumption by these sectors, this will enable us to make regional, sector-wise policy simulations and forecasts. The authors of this paper are working on this exercise to extend the research umbrella to other consumer types at the regional level. Another realm of importance to this kind of research indeed to future continuing research - are the recently announced major projects in certain Saudi cities, such as plans for the world's biggest city park. Future research should be tailored to account for the larger future demand these projects may cause. 


\section{Endnotes}

${ }^{1}$ Medium-sized firms are those with 50-249 employees, as per the GaStat industrial survey (2018).

${ }^{2}$ As we do not have region-specific industrial value added, we cannot compare elasticities in terms of regional industrial income level. Hence, we use overall regional GDPs for comparison purposes.

${ }^{3}$ For the EOA, SOA and WOA, the declines were, respectively, $-17 \%,-14 \%$ and $-1 \%$ in 2015 and $-4 \%,-20 \%$ and $-9 \%$ in 2019. The COA saw positive growth in both years. 


\section{References}

Adeyemi, Olutomi I., and Lester C. Hunt. 2014. "Accounting for Asymmetric Price Responses and Underlying Energy Demand Trends in OECD Industrial Energy Demand." Energy Economics 45:435-444. DOI: 10.1016/j.eneco.2014.07.012

Adeyemi, Olutomi I., David C. Broadstock, Mona Chitnis, Lester C. Hunt, and Guy Judge. 2010. "Asymmetric Price Responses and the Underlying Energy Demand Trend: Are They Substitutes or Complements? Evidence from Modelling OECD Aggregate Energy Demand." Energy Economics 32(5):1157-1164. DOI: 10.1016/j.eneco.2010.04.003

Agnolucci, Paolo. 2010. "Stochastic Trends and Technical Change: The Case of Energy Consumption in the British Industrial and Domestic Sectors." The Energy Journal 31(4):111-136. DOI: 10.5547/issn0195-6574-ej-vol31-no4-5

Al Awadhi, Mohammad A., and Mohamed Nagy Eltony. 2004. "Industrial Energy Policy: A Case Study of the Demand in Kuwait." Working Paper 0405, Economic Research Forum, Giza, Egypt, January.

Alarenan, Shahad, Anwar A. Gasim, and Lester C. Hunt. 2020. "Modelling Industrial Energy Demand in Saudi Arabia." Energy Economics 85:104554. DOI: 10.1016/j.eneco.2019.104554

Al Dubyan, Mohammad, and Anwar A. Gasim. 2020. "Energy Price Reform in Saudi Arabia: Modeling the Economic and Environmental Impact and Understanding the Demand Response." KAPSARC Discussion Paper, King Abdullah Petroleum Studies and Research Center, Riyadh, Saudi Arabia. DOI: 10.30573/ks--2020-dp12

Alkhathlan K., Javid M. 2015. "Carbon emissions and oil consumption in Saudi Arabia." Renewable and Sustainable Energy Reviews, (48): 105-111. DOI: 10.1016/j.rser.2015.03.072
Arisoy, Ibrahim, and Ilhan Ozturk. 2014.

"Estimating Industrial and Residential Electricity Demand in Turkey: A Time Varying Parameter Approach." Energy 66:959-964. DOI: 10.1016/j. energy.2014.01.016

Beenstock, Michael, and Alan Dalziel. 1986. "The demand for energy in the UK: a general equilibrium analysis." Energy Economics 8 (2) (1986), pp. 90-98. DOI: 10.1016/0140-9883(86)90033-2

Beenstock, Michael, Ephraim Goldin, and Dan Nabot. 1999. "The Demand for Electricity in Israel." Energy Economics 21(2):168-183. DOI: 10.1016/ S0140-9883(98)00005-X

Beenstock, Michael, and Patrick Wilcocks. 1983. "Energy and Economic Activity: A Reply to Kouris." Energy Economics 5(3):212-212. DOI: 10.1016/0140-9883(83)90064-6

Beenstock, Michael, and P. Willcocks. 1981. "Energy Consumption and Economic Activity in Industrialized Countries: The Dynamic Aggregate Time Series Relationship." Energy Economics 3(4):225-232. DOI: 10.1016/0140-9883(81)90023-2

Bernstein, Ronald, and Reinhard Madlener. 2015. "Short- and Long-run Electricity Demand Elasticities at the Subsectoral Level: A Cointegration Analysis for German Manufacturing Industries." Energy Economics 48:178-187. DOI: 10.1016/j. eneco.2014.12.019

Bose, Ranjan Kumar, and Megha Shukla. 1999. "Elasticities of Electricity Demand in India." Energy Policy 27(3):137-146. DOI: 10.1016/ S0301-4215(99)00011-7

Burke, Paul J., and Abayasekara Ashani. 2018. "The price elasticity of electricity demand in the United States: A three-dimensional analysis." Energy Journal 39 (2). DOI: 10.5547/01956574.39.2.pbur 
Campbell, Alrick. 2018. "Price and Income Elasticities of Electricity Demand: Evidence from Jamaica." Energy Economics 69:19-32. DOI: 10.1016/j.eneco.2017.10.040

Castle, Jennifer L., David F. Hendry, and Andrew B. Martinez. 2017. "Evaluating Forecasts, Narratives and Policy Using a Test of Invariance." Econometrics 5(3):39. Accessed October 21, 2021. doi:10.3390/ econometrics5030039.

Castle Jennifer L., and David F. Hendry. 2019. Modelling our Changing World. Part of Palgrave Texts in Econometrics series. Basingstoke, United Kingdom: Springer Nature. doi:10.1007/978-3-030-21432-6.

Chang, Yoosoon, and Eduardo Martinez-Chombo. 2003. "Electricity Demand Analysis Using Cointegration and Error-correction Models with Time Varying Parameters: The Mexican Case." Working Paper 2003-10, Rice University Department of Economics, Houston, Texas.

Chang, Yoosoon, Chang Sik Kim, J. Isaac Miller, Joon Y. Park, and Sungkeun Park. 2014. "Timevarying Long-run Income and Output Elasticities of Electricity Demand with an Application to Korea." Energy Economics 46:334-347. DOI: 10.1016/j. eneco.2014.10.003

Chepkemoi, Joyce. 2019. "The World's Largest Industrial Areas." World Atlas. June 10. Accessed November 11, 2020. https://www.worldatlas.com/ articles/world-s-largest-industrial-areas.html.

Cialani, Catia, and Reza Mortazavi. 2018.

"Household and Industrial Electricity Demand in Europe." Energy Policy 122:592-600. DOI: 10.1016/j.enpol.2018.07.060
Clements, Michael P., and David F. Hendry. 1998. Forecasting Economic Time Series. Cambridge: Cambridge University Press.

Csereklyei, Zsuzsanna. 2020. "Price and Income Elasticities of Residential and Industrial Electricity Demand in the European Union." Energy Policy 137, 111079. DOI: 10.1016/j.enpol.2019.111079

Damoom, Mohammed M., Suhairul Hashim, Mohammed S. Aljohani, and Muneer Aziz Saleh. 2018. "Adding sustainable sources to the Saudi Arabian electricity sector." The Electricity Journal, Volume 31, Issue 4, Pages 20-28. DOI: 10.1016/j. tej.2018.05.005

Dargay, Joyce. M. 1992. "The Irreversible Effects of High Oil Prices: Empirical Evidence for the Demand for Motor Fuels in France, Germany and the UK." In Energy Demand: Evidence and Expectations, edited by D. Hawdon, 165-182. Guildford, United Kingdom: Surrey University Press.

Dickey, David A., and Wayne A. Fuller. 1981. "Likelihood ratio statistics for autoregressive time series with a unit root." Econometrica, 49 (4), pp. 1057-1072. DOI: 0012-9682(198107)49:4\%3C1057: LRSFAT\%3E2.0.CO;2-4

Dilaver, Zafer, and Lester C. Hunt. 2011. "Industrial Electricity Demand for Turkey: A Structural Time Series Analysis." Energy Economics 33(3):426-436. DOI: 10.1016/j.eneco.2010.10.001

Doornik, Jurgen A. 2009. "Autometrics." In The Methodology and Practice of Econometrics, edited by J. L. Castle and N. Shepard, 88-121. Oxford: Oxford University Press.

Doornik, Jurgen A., and David F. Hendry. 2018. Empirical Econometric Modelling Using PcGive. vol. I, 8th ed. London: Timberlake Consultants Press. 
Durand-Lasserve, Olivier, and Fatih Karanfil. 2021. "Fiscal Policy for Stability in Oil-Exporting Countries: From the Old Problems to the Challenges of COVID19." KAPSARC Commentary paper, King Abdullah Petroleum Studies and Research Center, Riyadh, Saudi Arabia.

Durbin, James, and Siem Jan Koopman. 2012. Time Series Analysis by State Space Methods. Number 38, Oxford University Press.

El Gammal, Farouk M., and El-Sayed El-Bushra. 1986. "Geographic analysis of manufacturing industry in Saudi Arabia." Geo Journal 13, 157-171. 10.1007/BF00212718

Ericsson, Neil R. 2012. "Detecting Crises, Jumps, and Changes in Regime." Working Paper, Federal Reserve Board of Governors, Washington, DC.

FBP. 2019. Fiscal Balance Program. "Saudi Vision 2030 Realization Program. A program by Vision 2030, Kingdom of Saudi Arabia." Accessed October 20, 2021. https://www.vision2030.gov.sa/v2030/vrps/ $\mathrm{fsp} /$

Gautam, Tej K., and Krishna P. Paudel. 2018. "Estimating Sectoral Demands for Electricity Using the Pooled Mean Group Method." Applied Energy 231:54-67.

General Authority for Statistics (GaStat). 2018. "Industrial Activity Survey 2018." Accessed February 25, 2021. https://www.stats.gov.sa/sites/default/files/ nskh_mn_jdwl_msh_Insht_Isny_Inhyy_2018_-_ Injlyzy.xlsx.

Guinness World Records (GWR). 2019. "Largest Water Desalination Plant." Accessed November 11, 2020. https://www.guinnessworldrecords.de/worldrecords/425709-largest-water-desalination-plant.
Halvorsen, Robert, 1972. "Residential electricity:

Demand and supply." Harvard University,

Environmental Systems Program. Discussion Paper 71-77.

Harvey, Andrew C. 1989. Forecasting, Structural Time Series Models and the Kalman Filter.

Cambridge: Cambridge University Press.

Hasanov, Fakhri Javanshir. 2019. "Theoretical Framework for Industrial Electricity Consumption Revisited: Empirical Analysis and Projections for Saudi Arabia." KAPSARC Discussion Paper. King Abdullah Petroleum Studies and Research Center, Riyadh, Saudi Arabia. DOI: 10.30573/ KS--2019-DP66.

- - - 2021. "Theoretical Framework for Industrial Energy Consumption Revisited: The Role of Demographics." Energy Reports 7:2178-2200. DOI: 10.1016/j.egyr.2021.04.002

Hasanov, Fakhri Javanshir, Frederick L. Joutz, Jeyhun I. Mikayilov, and Muhammad Javid. 2020. "KGEMM: A Macroeconometric Model for Saudi Arabia." KAPSARC Discussion Paper. King Abdullah Petroleum Studies and Research Center, Riyadh, Saudi Arabia. DOI: 10.30573/KS--2020-DP04

Hasanov, Fakhri Javanshir, and Jeyhun I. Mikayilov. 2020. "Revisiting Energy Demand Relationship: Theory and Empirical Application." Sustainability 12(7):2919. DOI: 10.3390/su12072919

Holtedahl, Pernille, and Frederick L. Joutz. "Residential electricity demand in Taiwan." Energy Economics 26 (2) (2004), pp. 201-224. DOI: 10.1016/j.eneco.2003.11.001

Hughes, Jonathan E., Christopher R. Knittel, and Daniel Sperling. 2008. "Evidence of a Shift in the Short-run Price Elasticity of Gasoline Demand." The Energy Journal 29(1):113-134. 
Hunt, Lester C., Guy Judge, and Yashushi Ninomiya. 2003a. "Underlying Trends and Seasonality in UK Energy Demand: A Sectoral Analysis." Energy Economics 25(1):93-118. DOI: 10.1016/ S0140-9883(02)00072-5

Hunt, Lester C., Guy Judge, and Yashushi Ninomiya. 2003b. "Modelling Underlying Demand Trends." In Energy in a Competitive Market: Essays in Honour of Colin Robinson, 140-174. Cheltenham, UK: Edward Elgar.

Huntington, Hillard G. 2006. "A note on Price Asymmetry as Induced Technical Change." The Energy Journal 27(3):1-8. DOI: 10.2307/23296987

Inglesi-Lotz, Roula. 2011. "The Evolution of Price Elasticity of Electricity Demand in South Africa: A Kalman Filter Application." Energy Policy 39(6):3690-3696. DOI: 10.1016/j.enpol.2011.03.078

Jarque, Carlos M., and Anil K. Bera. 1987. "A test for normality of observations and regression residuals." International Statistical Review 55, pp. 163-172.

Jamil, Faisal, and Eatzaz Ahmad. 2011. "Income and Price Elasticities of Electricity Demand: Aggregate and Sector-wise Analyses." Energy Policy 39(9):5519-5527. DOI: 10.1016/j.enpol.2011.05.010

Javid, Muhammad, and Abdul Qayyum. 2014. "Electricity Consumption-GDP Nexus in Pakistan: A Structural Time Series Analysis." Energy 64:811817. DOI: 10.1016/j.energy.2013.10.051

Kamerschen, David R., and David V. Porter. 2004. "The Demand for Residential, Industrial and Total Electricity, 1973-1998." Energy Economics 26(1):87100. DOI: 10.1016/S0140-9883(03)00033-1
Kim, Hyo-Jin, Gyeong-Sam Kim, and Seung-Hoon Yoo. 2019. "Demand Function for Industrial Electricity: Evidence from South Korean Manufacturing Sector." Sustainability 11(18):5112. DOI: 10.3390/su11185112

KAPSARC. 2020. "kapsarc.opendatasoft.com." Accessed September 27, 2020. https://kapsarc. opendatasoft.com/explore/dataset/electricityprices-in-saudi-arabia0/information/?disjunctive. consumption_slab\&disjunctive.sector.

Kingdom of Saudi Arabia Government. 1975. "Jubail Royal Decree." Accessed November 11, 2020. https://laws.boe.gov.sa/BoeLaws/ Laws/Viewer/0b571a4f-b362-4c62-ac9c$3 a 93 c 67179 b 9$ ? lawld=0ad8fc8e-73f8-48b6-9c5ba9a700f2974b.

Kouris, George. 1983a. "Fuel Consumption for Road Transport in the USA." Energy Economics 5(2):8999. DOI: 10.1016/0140-9883(83)90015-4

Kouris, George. 1983b. "Energy Consumption and Economic Activity in Industrialized Economies-A Note." Energy Economics 5(3):207-212. DOI: 10.1016/0140-9883(83)90063-4

Liddle, Brant, and Fakhri Javanshir Hasanov. 2021. "Industry Electricity Price and Output Elasticities for High-income and Middle-income Countries." Empirical Economics 1-27. DOI: 10.1007/ s00181-021-02053-z

Ljung, Greta M., and George E. P. Box. 1978. "On a Measure of a Lack of Fit in Time Series Models." Biometrika. 65 (2): 297-303. 


\section{References}

Lopez-Ruiz, Hector G., Jorge Blazquez, and Fakhri Javanshir Hasanov. 2019. "Estimating the Saudi Arabian Regional GDP Using Satellite Nighttime Light Images." KAPSARC Discussion Paper. King Abdullah Petroleum Studies and Research Center, Riyadh, Saudi Arabia. doi:10.30573/ KS-2019-DP80.

Mikayilov, Jeyhun I., Abdulelah Darandary, Ryan Alyamani, Fakhri Javanshir Hasanov, and Hatem Alatawi. 2020. "Regional Heterogeneous Drivers of Electricity Demand in Saudi Arabia: Modeling Regional Residential Electricity Demand." Energy Policy 146:111796. DOI: 10.1016/j.enpol.2020.111796

Mikayilov, Jeyhun I., Fakhri Javanshir Hasanov, Carlo A. Bollino, and Ceyhun Mahmudlu. 2017. "Modeling of Electricity Demand for Azerbaijan: Time-varying Coefficient Cointegration Approach." Energies 10(11):1918. DOI: 10.3390/en10111918

Mount, Timothy D., L. Duane Chapman, and Timothy J. Tyrell. 1973. "Electricity demand in the United States: An econometric analysis." In: Conference on Energy, Demand, Conservation, and Institutional Problems, Cambridge, Massachusetts, Feb. 12.

Mundaca, Gabriela. 2017. "How much can $\mathrm{CO}_{2}$ emissions be reduced if fossil fuel subsidies are removed?" Energy Economics, (64): 91-104. DOI: 10.1016/j.eneco.2017.03.014

Nachet Said, and Marie-Claire Aoun. 2015. "The Saudi Electricity Sector: Pressing Issues and Challenges." The Institut Français des Relations Internationales (IFRI). Accessed September 27, 2020. https://www.ifri.org/sites/default/files/atoms/ files/note_arabie_saoudite_vf.pdf.
Neto, David. 2012. "Testing and Estimating Time-varying Elasticities of Swiss Gasoline Demand." Energy Economics 34(6):1755-1762. DOI: 10.1016/j.eneco.2012.07.009

National Industrial Development and Logistics Program (NIDLIP). 2019. Accessed October 20, 2021. http://www.arabia-saudita.it/files/ news/2019/02/nidlp_2019_en.pdf

Nordhaus, William D. 1975. "The Demand for Energy: An International Perspective." Cowles Foundation for Research in Economics, Yale University.

Nyblom, Jukka, and Andrew C. Harvey. 2001. "Testing Against Smooth Stochastic Trends." Journal of Applied Econometrics 16:415-429. DOI: 10.1002/ jae.604

- - . 2000. "Tests of Common Stochastic Trends." Econometric Theory 16:176-199.

Park, Joon Y., and Sang B. Hahn. 1999.

"Cointegrating Regressions with Time Varying Coefficients." Econometric Theory 15(5):664-703.

Park, Sung Y., and Guochang Zhao. 2010. "An Estimation of US Gasoline Demand: A Smooth Time-varying Cointegration Approach." Energy Economics 32(1):110-120. DOI: 10.1016/j. eneco.2009.10.002

Peñasco, Cristina, Pablo del Río, and Desiderio Romero-Jordán. 2017. "Gas and Electricity Demand in Spanish Manufacturing Industries: An Analysis Using Homogeneous and Heterogeneous Estimators." Utilities Policy 45:45-60. DOI: 10.1016/j. jup.2017.01.005

Petro Rabigh. (n.d.). "Who We Are." Accessed September 29, 2020. https://www.petrorabigh.com/ en/AboutPRC/WhoWeAre/Pages/ourstory.aspx. 
Polemis, Michael. L. 2007. "Modeling industrial energy demand in Greece using cointegration techniques." Energy Policy, Elsevier, vol. 35(8), pages 4039-4050.

Saudi Arabian Monetary Authority (SAMA). 2019. "Annual Statistics 2019: July 2020 Release." Accessed September 29, 2020. http://www. sama.gov.sa/en-US/EconomicReports/Pages/ YearlyStatistics.aspx.

- - - 2020. "Annual Statistics 2020: May 2021 Release." Accessed October 20, 2021. https:// www.sama.gov.sa/en-us/EconomicReports/pages/ YearlyStatistics.aspx

Saudi Aramco. 2016. "Saudi Aramco, Air Products, and ACWA Power to Form Over \$8 Billion Gasification/Power Joint Venture at Jazan Economic City." Accessed November 16, 2020. https:// www.aramco.com/en/news-media/news/2018/ jv-aramco-airproducts-acwapower-jazan-gasification.

Saudi Authority for Industrial Cities and Technology Zones (MODON). 2020. "MODON Home Page." Accessed September 29, 2020. https://www.modon. gov.sa/en/Pages/default.aspx.

Saudi Basic Industries Corporation (SABIC). 2018. "SABIC Board of Directors' Report 2018." Accessed November 11, 2020. https://www.sabic.com/assets/ en/Images/SABIC-Board-of-Directors-Report-en_ tcm1010-17552.pdf.

Saudi Electricity Company (SEC). 2015. "Annual Report 2015." Accessed October 20, 2021. https:// www.se.com.sa/en-us/Pages/AnnualReports.aspx

Saudi Electricity Company (SEC). 2020. "Board of Directors' Report 2020." Accessed October 20, 2021. https://www.se.com.sa/en-us/Pages/ ShareHoldersReports.aspx
Saudi Industrial Development Fund (SIDF). 2020. "SIDF Home Page." Accessed September 29, 2020. https://www.sidf.gov.sa/en/Pages/Home.aspx.

Saudi Press Agency. 2020. Accessed September 29, 2020. https://www.spa.gov.sa/viewfullstory. php?lang=en\&newsid=2074935.

Saudi Vision 2030 (SV2030). 2017. "National Industrial Development and Logistic Program." Accessed September 29, 2020. https://vision2030. gov.sa/sites/default/files/attachments/NIDLP\%20 Delivery\%20Plan\%20-\%20English\%20Jan\%202019. pdf.

Shirani-Fakhr, Zohreh, Rahman Khoshakhlagh, and Alimorad Sharifi. 2015. "Estimating Demand Function for Electricity in Industrial Sector of Iran Using Structural Time Series Model (STSM)." Applied Econometrics and International Development 15(1):143-160.

Steinbuks, Jevgenijs. 2012. "Interfuel Substitution and Energy Use in the UK Manufacturing Sector." The Energy Journal 33(1):1-30. DOI: 10.5547/ ISSN0195-6574-EJ-Vol33-No1-1

Wang, Nan, and Gento Mogi. 2017. "Industrial and Residential Electricity Demand Dynamics in Japan: How Did Price and Income Elasticities Evolve from 1989 to 2014?" Energy Policy 106:233-243. DOI: 10.1016/j.enpol.2017.03.066

Oxford Economics (OE) Country Economic Forecast Saudi Arabia. 2020. December 16, 2020. Accessed October 20, 2021. https://www.oxfordeconomics. com/my-oxford/publications/600929?utm source=halo\&utm_medium=release_email\&utm_ content=content_item_600929\&utm_ campaign=Country_Economic_Forecasts 


\section{References}

Yanbu Industrial City (YIC) Quarterly Report. 2016. "Yanbu Industrial City Economic Review 4th quarter 2016." Accessed October 20, 2021. https://www.jeg. org.sa/sites/default/files/library/files/4th-Q-2016.pdf 
Table A1. Regional distribution of industrial activity and electricity consumption by sector.

\begin{tabular}{|c|c|c|c|c|c|}
\hline \multirow{2}{*}{ Industry Type } & \multicolumn{4}{|c|}{ Number of Firms Per Region by Type } & \multirow{2}{*}{$\begin{array}{c}\text { Electricity Cons } \\
\text { (Thousand SAR } \\
\text { Per Industry }\end{array}$} \\
\hline & COA & WOA & EOA & SOA & \\
\hline Mining of Coal and Lignite & 6 & 0 & 1 & 0 & 27.76546123 \\
\hline Extraction of Crude Oil and Natural Gas & 7 & 7 & 54 & 4 & 6749129.031 \\
\hline Mining of Metal Ores & 21 & 19 & 10 & 1 & 50347.71684 \\
\hline Other Activities Related to Mining and Quarrying & 170 & 113 & 99 & 17 & 78505.88943 \\
\hline Activities of Mining Support Services & 35 & 37 & 70 & 18 & 83686.5277 \\
\hline Manufacture of Food Products & 3553 & 4364 & 2361 & 1617 & 2291710.983 \\
\hline Manufacture of Beverages & 370 & 386 & 202 & 63 & 296953.1123 \\
\hline Manufacture of Tobacco & 15 & 35 & 12 & 24 & 632.1976106 \\
\hline Manufacture of Textiles & 853 & 819 & 690 & 29 & 302080.7179 \\
\hline Manufacture of Clothes & 10760 & 11734 & 6466 & 4000 & 193023.7532 \\
\hline $\begin{array}{l}\text { Manufacture of Leather Products and Other Related } \\
\text { Products }\end{array}$ & 48 & 54 & 26 & 20 & 9614.526628 \\
\hline Manufacture of Wood, Wood Products, and Foam & 1643 & 1783 & 1063 & 509 & 227640.7313 \\
\hline Manufacture of Paper and Other Related Products & 149 & 110 & 92 & 6 & 438619.9222 \\
\hline Printing and reproduction of recorded media & 423 & 458 & 374 & 178 & 256146.2107 \\
\hline Manufacture of coke and refined petroleum products & 32 & 41 & 51 & 13 & 2450082.462 \\
\hline Manufacture of chemicals and chemical products & 471 & 448 & 549 & 61 & 3895627.859 \\
\hline $\begin{array}{l}\text { Manufacture of products and preparations } \\
\text { pharmaceutical }\end{array}$ & 34 & 43 & 18 & 4 & 62278.3573 \\
\hline Manufacture of rubber and plastics products & 247 & 285 & 243 & 18 & 541627.1617 \\
\hline Manufacture of other non-metallic mineral products & 1404 & 1492 & 1339 & 451 & 559575.2704 \\
\hline Manufacture of basic metals & 209 & 180 & 185 & 35 & 987284.1737 \\
\hline Manufacture of fabricated metal products & 5988 & 7352 & 4415 & 3522 & 448376.1467 \\
\hline $\begin{array}{l}\text { Manufacture of computer, electronic and optical } \\
\text { products }\end{array}$ & 69 & 49 & 33 & 1 & 16758.1053 \\
\hline Manufacture of electrical equipment & 240 & 178 & 152 & 50 & 591984.0118 \\
\hline Manufacture of machinery and equipment n.e.c. & 141 & 138 & 72 & 30 & 188268.4715 \\
\hline $\begin{array}{l}\text { Manufacture of motor vehicles, trailers and } \\
\text { semi-trailers }\end{array}$ & 135 & 112 & 85 & 7 & 39539.51592 \\
\hline Manufacture of other transport equipment & 21 & 13 & 14 & 3 & 35756.55005 \\
\hline Manufacture of furniture & 3910 & 3818 & 1540 & 636 & 356893.9062 \\
\hline Other manufacturing & 185 & 158 & 119 & 59 & 53292.95476 \\
\hline Repair and installation of machinery and equipment & 3874 & 5162 & 1991 & 1421 & 108785.756 \\
\hline Electicity, gas, steam, and air conditioning supply & 305 & 262 & 166 & 58 & 1666769.645 \\
\hline Water collection, processing, and supply & 705 & 804 & 332 & 172 & 133465.7106 \\
\hline Sanitation & 62 & 54 & 19 & 5 & 30890.22789 \\
\hline $\begin{array}{l}\text { Activities of waste collection, processing, disposal, } \\
\text { and recycling }\end{array}$ & 135 & 104 & 59 & 0 & 26816.00028 \\
\hline $\begin{array}{l}\text { Other processing activities and waste management } \\
\text { services }\end{array}$ & 11 & 4 & 4 & 0 & 760.4955191 \\
\hline
\end{tabular}

Source: GaStat 2018 Industrial Survey. 
Table A2. Industrial cities and oases in Saudi Arabia and associated information.

Industrial Cities

\begin{tabular}{|c|c|c|c|c|c|}
\hline Region & Industrial City & $\begin{array}{l}\text { Year of } \\
\text { Creation }\end{array}$ & $\begin{array}{l}\text { Number of } \\
\text { Factories }\end{array}$ & $\begin{array}{l}\text { Total Land } \\
\left(\mathbf{k m}^{2}\right)\end{array}$ & Status \\
\hline \multirow{11}{*}{ Central } & Riyadh 1st Industrial City & 1973 & 64 & 0.5 & Fully developed \\
\hline & Riyadh 2nd Industrial City & 1976 & 1119 & 19 & Fully developed \\
\hline & Riyadh 3rd Industrial City & 2010 & 15 & 1 & Fully developed \\
\hline & Sudair City for Industry and Businesses & 2009 & 265 & 265 & $16.9 \mathrm{~km}^{2}$ developed \\
\hline & Qassim 1st Industrial City & 1980 & 142 & 1.5 & Fully developed \\
\hline & Qassim 2nd Industrial City & 2012 & 31 & 118 & $2 \mathrm{~km}^{2}$ developed \\
\hline & Al-Kharj Industrial City & 2009 & 375 & 99 & $24 \mathrm{~km}^{2}$ developed \\
\hline & Ha'il Industrial City & 2003 & 96 & 3.88 & $3 \mathrm{~km}^{2}$ developed \\
\hline & Shaqraa Industrial City & 2011 & 327 & 10 & $1 \mathrm{~km}^{2}$ developed \\
\hline & Al-Zulfi Industrial City & 2010 & 8 & 18 & $1 \mathrm{~km}^{2}$ developed \\
\hline & Dhurma Industrial city & 2003 & 16 & 11.5 & $3.85 \mathrm{~km}^{2}$ developed \\
\hline \multirow{8}{*}{ Eastern } & Dammam 1st Industrial City & 1973 & 170 & 2.4 & Fully developed \\
\hline & Dammam 2nd Industrial City & 1978 & 1056 & 25 & Fully developed \\
\hline & Dammam 3rd Industrial City & 2012 & 176 & 48 & $10 \mathrm{~km}^{2}$ developed \\
\hline & Al-Ahsa 1st Industrial City & 1981 & 144 & 1.5 & Fully developed. \\
\hline & Al-Ahsa 2nd Industrial City & 2013 & 15 & 301.6 & $4 \mathrm{~km}^{2}$ developed \\
\hline & Ar'ar Industrial City & 2009 & 7 & 2 & $1 \mathrm{~km}^{2}$ developed \\
\hline & Hafr Al-Batin Industrial City & 2011 & 11 & 100 & $1.5 \mathrm{~km}^{2}$ developed \\
\hline & Wa'ad Al-Shamal Industrial City & 2012 & - & 290 & Under development \\
\hline \multirow{7}{*}{ Western } & Jeddah 1st Industrial City & 1971 & 1059 & 12 & Fully developed \\
\hline & Jeddah 2nd Industrial City & 2009 & 275 & 8 & Fully developed \\
\hline & Jeddah 3rd Industrial City & 2012 & 539 & 80 & $24 \mathrm{~km}^{2}$ developed \\
\hline & Rabigh Industrial City & 2015 & - & 75.5 & $2 \mathrm{~km}^{2}$ developed \\
\hline & Al-Madina Al-Munawwara Industrial City & 2003 & 234 & 17 & $10 \mathrm{~km}^{2}$ developed \\
\hline & Makkah Al-Mukarrama Industrial City & 1985 & 74 & 0.73 & Fully developed \\
\hline & Tabuk Industrial City & 2003 & 73 & 4 & $2.9 \mathrm{~km}^{2}$ developed \\
\hline \multirow{5}{*}{ Southern } & Al-Baha 1st Industrial City & 2012 & 20 & 3 & $1.3 \mathrm{~km}^{2}$ developed \\
\hline & Al-Baha 2nd Industrial City & - & - & - & - \\
\hline & Assir Industrial City & 1990 & 157 & 2.7 & Fully developed. \\
\hline & Najran Industrial City & 2003 & 30 & 6.5 & $3.6 \mathrm{~km}^{2}$ developed \\
\hline & Jazan Industrial City & 2009 & 53 & 39 & $\begin{array}{l}2.975 \mathrm{~km}^{2} \\
\text { developed }\end{array}$ \\
\hline \multicolumn{6}{|c|}{ MODON Oasis } \\
\hline Central & Modon Oasis in Qassim & 2012 & 31 & 11.8 & $2 \mathrm{~km}^{2}$ developed \\
\hline \multirow{2}{*}{ Eastern } & Modon Oasis in Al-Ahsa & 2013 & 9 & 0.54 & Fully developed \\
\hline & Modon Oasis in Al-Jouf & 2003 & - & 3 & $0.98 \mathrm{~km}^{2}$ developed \\
\hline \multirow{2}{*}{ Western } & Modon Oasis in Jeddah & 2015 & 48 & 5 & $2.5 \mathrm{~km}^{2}$ developed \\
\hline & Modon Oasis in Yanbu & 2014 & - & 0.5 & Fully developed \\
\hline
\end{tabular}

*Includes factories that are producing, existing and under construction.

Source: MODON (2020). 


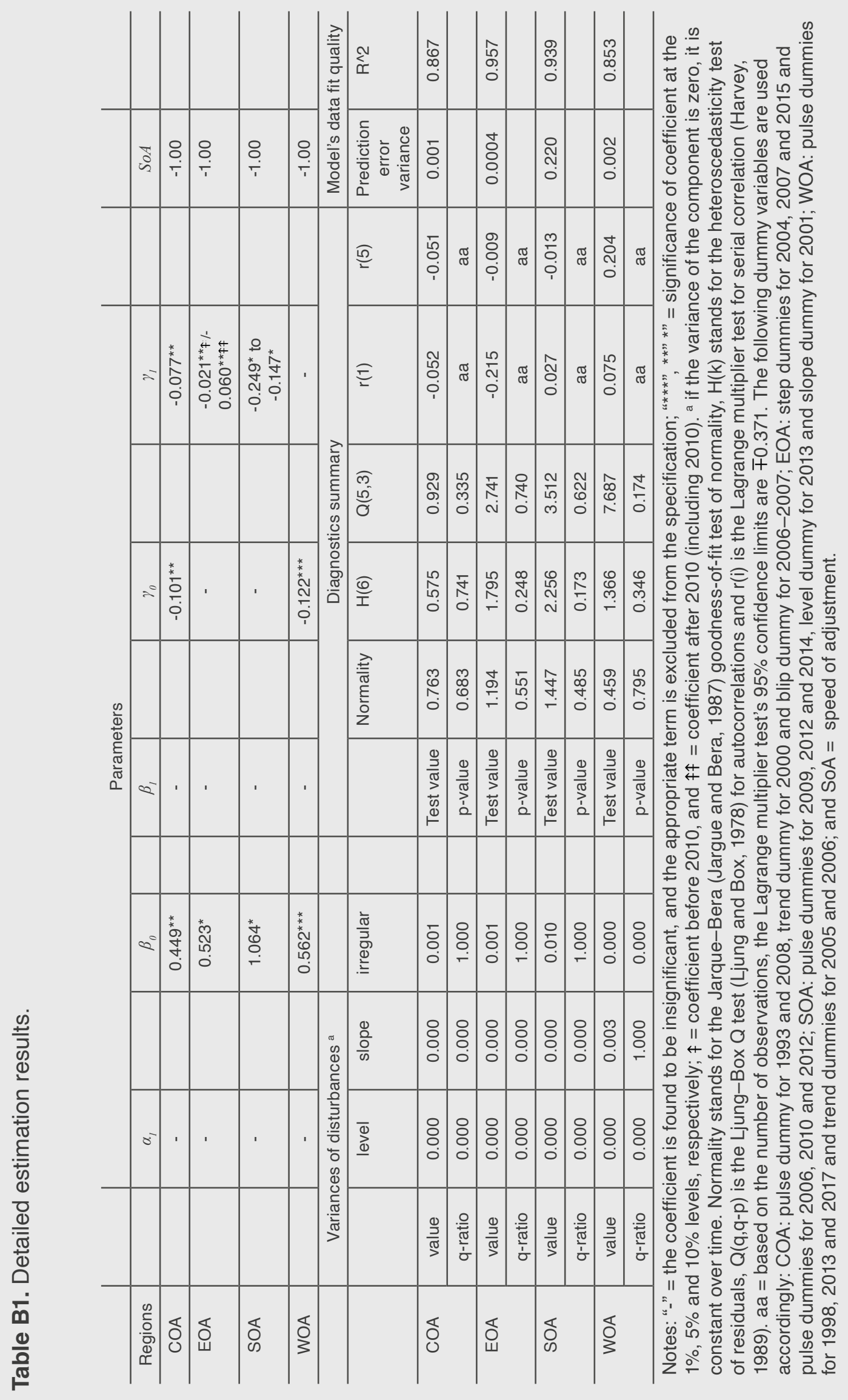




\section{Appendix C: Estimation results for the WOA region using the TVCC approach}

Table C1. Long-run estimation results using the TVCC approach.

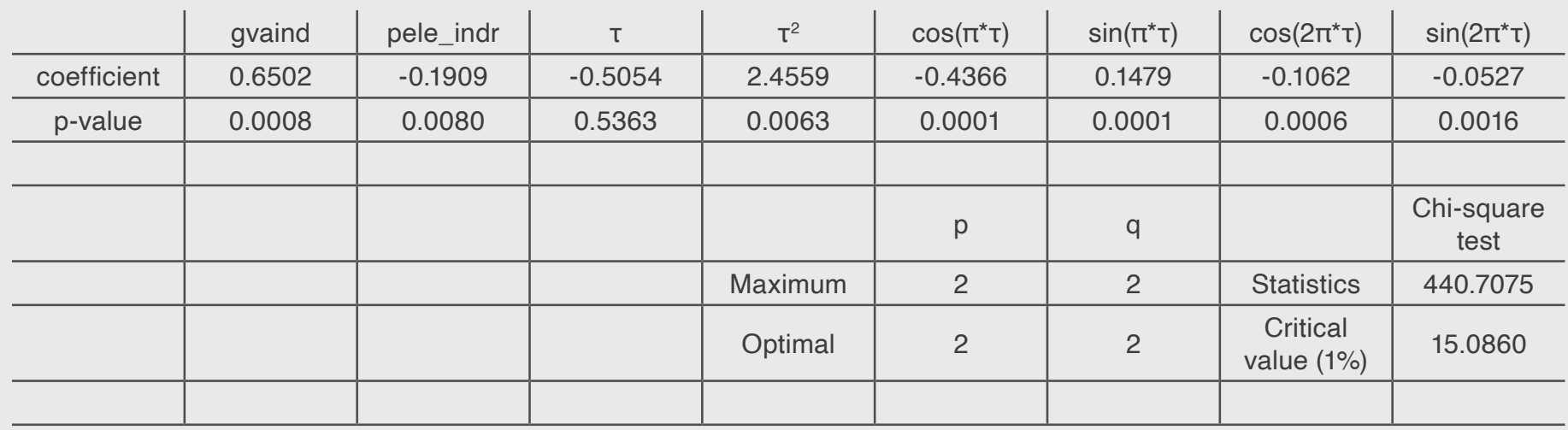

Notes: $\tau=\frac{t}{n}$, where $\mathrm{t}$ is time trend and $\mathrm{n}$ is sample size.The following indicator saturation dummies are selected using Autometrics machine learning algorithm (as done with the STSM approach): pulse dummies for 1998, 2013 and 2017 , trend dummies for 2005 and 2006. Optimal values of $p$ and $q$ are chosen based on SIC criterion. gvaind = industrial GVA; pele_indr = electricity price for industry in real terms. 


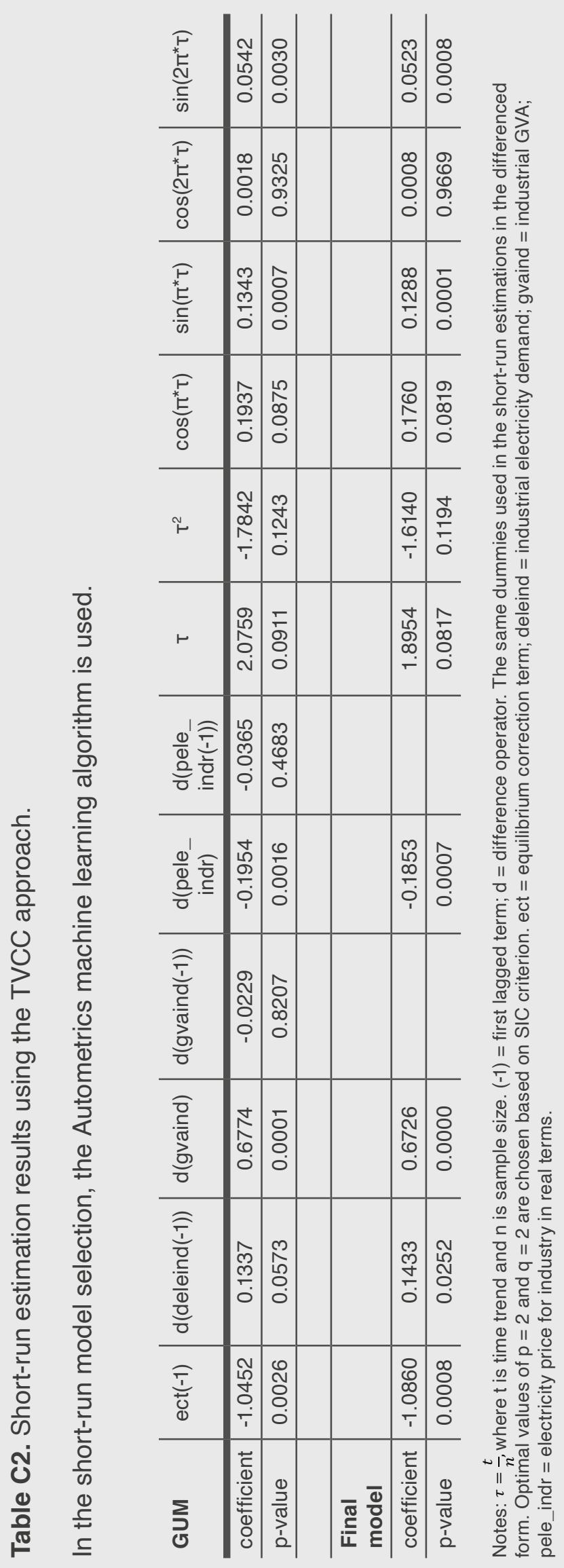


To get the outcome shown in Table C2, first, the optimal lag is chosen based on the SIC criterion, setting the maximum lag to two. Then, the maximum lag is set to two dependent variables and independent variables, and the ECT term and differenced dummy variables are entered into the initial GUM. The dependent and independent variables - with lags, ECT and varying intercept terms - are fixed, and the significance level is set at different tight levels until the $2.5 \%$ saturation dummies are reached. The algorithm did not choose any additional dummy. In the next step, the final search is done by fixing the dummies and varying intercept terms (unfixing the ECT term and dependent and independent variables, with lags as well) and setting the significance level at $10 \%$.

Table C3. Test results comparing the long- and short-run elasticities.

\begin{tabular}{l|c|c|c} 
& Income & Price & Wald test (Null Hypothesis: Long-run elasticity = Short-run elasticity) \\
\hline Long run & 0.6502 & -0.1909 & $p$-value $=0.8328$ \\
\hline Short run & 0.6726 & -0.1853 & p-value $=0.8949$
\end{tabular}

Figure C1. Stochastic trend using the TVCC approach (called the UEDT in the STSM approach).

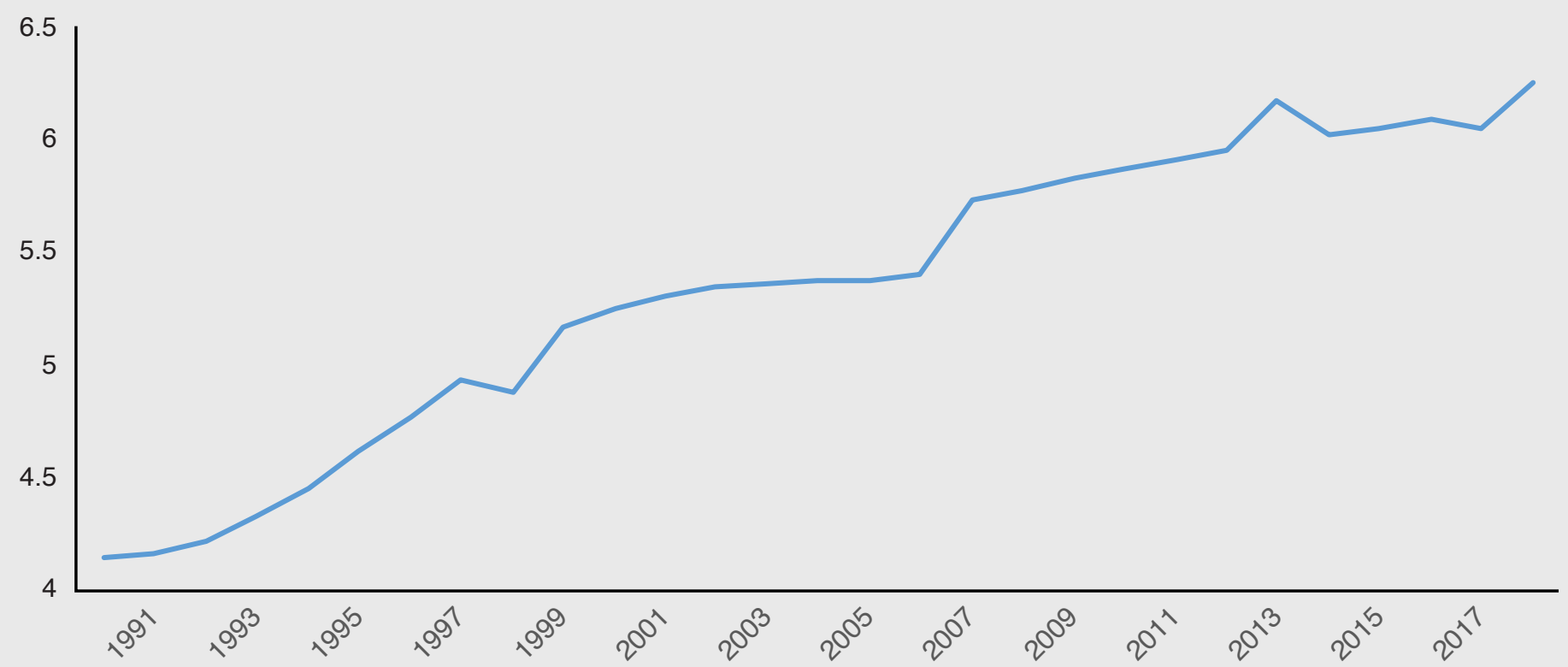

Source: Estimation results. 
Notes

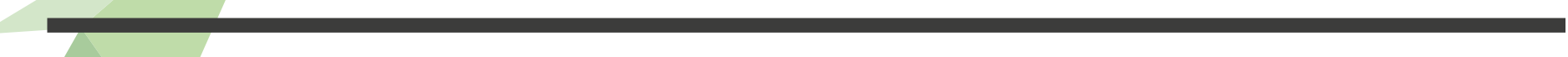




\section{Notes}


Notes

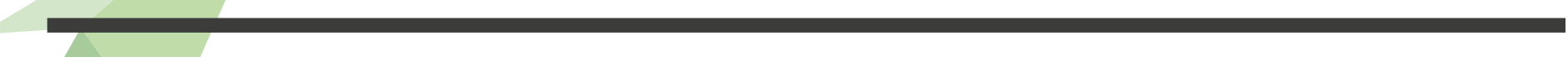




\section{About the Authors}

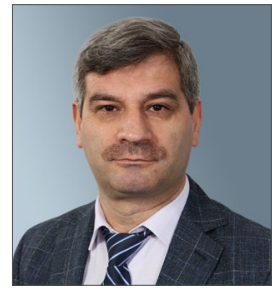

\section{Jeyhun I. Mikayilov}

Jeyhun is a research fellow at KAPSARC and leads the Modeling Energy Consumption and its Impacts in Saudi Arabia project. His primary research interests include but are not limited to applied time series econometrics, the economics of energy and environment, and sustainable development. He holds a Ph.D. in Applied Mathematics.

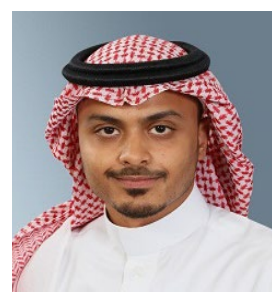

\section{Ryan Alyamani}

Ryan is a senior research analyst in the Energy and Macroeconomics program with a particular interest in natural resource economics and developing energy and economic models. Ryan holds a B.S. degree in Mechanical Engineering from Mercer University.

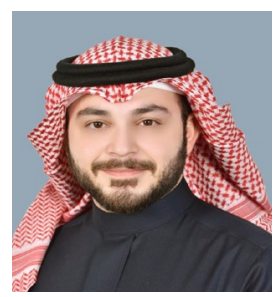

\section{Abdulelah Darandary}

Abdulelah is an economist and Research Associate at the King Abdullah Petroleum Studies and Research Center (KAPSARC). He primarily works with econometric modeling, with a research focus on macroeconomics and energy, international trade and investment flows, financial development, and public policy.

Abdulelah holds a master's degree in Applied Economics and a Bachelor of Banking and Financial Economics from the University of North Dakota.

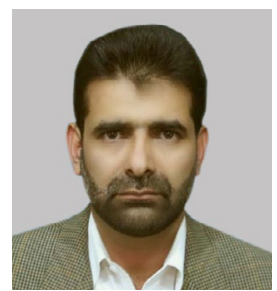

\section{Muhammad Javid}

Muhammad is a research fellow at KAPSARC. His research interests include but are not limited to economic development, the economics of energy and environment, and sustainable development. He holds a Ph.D. in Applied Economics.

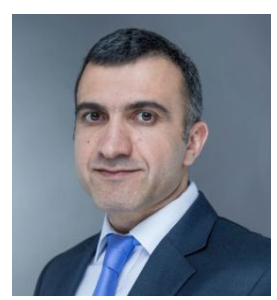

\section{Fakhri J. Hasanov}

Fakhri is a research fellow at KAPSARC and leads the KAPSARC Global Energy Macroeconometric Model (KGEMM) project. His research interests and experience span econometric modeling and forecasting, building and applying macroeconometric models for policy purposes, and energy economics, with a particular focus on natural resource rich countries. He holds a Ph.D. in Economics. 


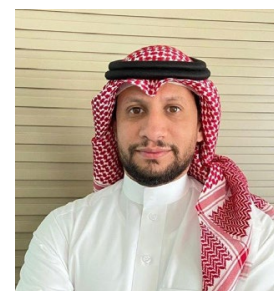

\section{Saleh T. AlTurki}

Saleh is Division Manager of the System Demand and Energy Forecasting Network Long-Term Planning Department at the Saudi Electricity Company. He has 14 years of experience in developing forecasting models and alternative demand scenarios, integrating the economic, demographic, and exogeneous factors affecting Saudi Arabia's peak demand and energy demand. Saleh holds a Master of Business Administration.

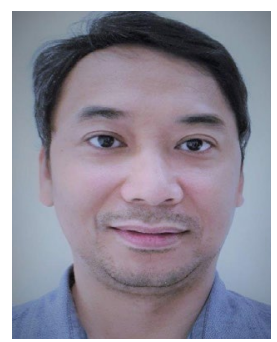

\section{Rey B. Arnaiz}

Rey is Load Forecast Engineer at the Saudi Electricity Company. He has 17 years of experience in the electricity industry, including load forecast development, distribution system modeling and analysis, and distribution system planning. Rey holds a B.Sc. in Electrical Engineering from the Cebu Institute of Technology.

\section{About the Project}

The KAPSARC Global Energy Macroeconometric Model (KGEMM) project aims to develop a domestic policy analysis tool that captures the interactions between the Saudi and global economies. Commonly available models are typically more focused on the global economy (and the major contributors to global GDP). They typically use an oversimplified representation of major oil and gas exporting economies to capture energy flows into the global system. They fail to take into account the importance of Saudi Arabia's energy sector, or the growing importance of the domestic Saudi economy as a driver of domestic demand and, hence, available oil exports. KGEMM covers the real, monetary, fiscal, external, energy and labor sectors of the Saudi economy. It takes a demand-side view of the economy with some supply-side representations. KGEMM has been developed by KAPSARC for the following purposes:

- To provide a representation of the Saudi economy that takes into account its particular features.

- To offer KAPSARC's stakeholders a macroeconometric model with which to evaluate different policy scenarios, such as energy price reforms, fiscal policy changes and the impacts of different oil price regimes.

- To connect the Kingdom's macroeconomic-energy environment with other models of the global economy.

KGEMM has a sound theoretical foundation. Its estimations are based on cutting-edge econometric methods used in developing and enhancing the model. It is easy to customize, so that it can address future research/policy questions. 
INAPSARC

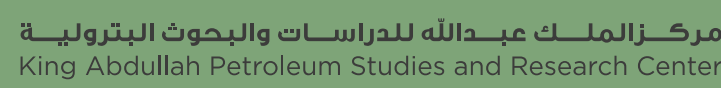

www.kapsarc.org 